\title{
The Impact of Different Absolute Solar Irradiance Values on Current Climate Model Simulations
}

\author{
DAVID H. RIND \\ NASA GISS, New York, New York \\ JUDITH L. LEAN \\ Space Science Division, Naval Research Laboratory, Washington D.C. \\ JEFFREY JONAS \\ Columbia University, New York, New York
}

(Manuscript received 25 February 2013, in final form 27 September 2013)

\begin{abstract}
Simulations of the preindustrial and doubled $\mathrm{CO}_{2}$ climates are made with the GISS Global Climate Middle Atmosphere Model 3 using two different estimates of the absolute solar irradiance value: a higher value measured by solar radiometers in the 1990s and a lower value measured recently by the Solar Radiation and Climate Experiment. Each of the model simulations is adjusted to achieve global energy balance; without this adjustment the difference in irradiance produces a global temperature change of $0.4^{\circ} \mathrm{C}$, comparable to the cooling estimated for the Maunder Minimum. The results indicate that by altering cloud cover the model properly compensates for the different absolute solar irradiance values on a global level when simulating both preindustrial and doubled $\mathrm{CO}_{2}$ climates. On a regional level, the preindustrial climate simulations and the patterns of change with doubled $\mathrm{CO}_{2}$ concentrations are again remarkably similar, but there are some differences. Using a higher absolute solar irradiance value and the requisite cloud cover affects the model's depictions of high-latitude surface air temperature, sea level pressure, and stratospheric ozone, as well as tropical precipitation. In the climate change experiments it leads to an underestimation of North Atlantic warming, reduced precipitation in the tropical western Pacific, and smaller total ozone growth at high northern latitudes. Although significant, these differences are typically modest compared with the magnitude of the regional changes expected for doubled greenhouse gas concentrations. Nevertheless, the model simulations demonstrate that achieving the highest possible fidelity when simulating regional climate change requires that climate models use as input the most accurate (lower) solar irradiance value.
\end{abstract}

\section{Introduction}

The sun's energy is the primary determinant of the earth's climate, which changes when there is an imbalance between incoming solar energy (at near-ultraviolet and visible wavelengths) and outgoing terrestrial energy (at infrared wavelengths). Measurements made by the Total Irradiance Monitor (TIM) on the Solar Radiation and Climate Experiment (SORCE) (Rottman et al. 2005) indicate that the total solar irradiance (TSI)

Corresponding author address: Judith L. Lean, Space Science Division, Naval Research Laboratory, 4555 Overlook Avenue, SW, Washington, DC 20375.

E-mail: judith.lean@nrl.navy.mil is $\sim 1361.3 \mathrm{~W} \mathrm{~m}^{-2}$ (Kopp and Lean 2011), which provides incoming solar energy of $340 \mathrm{~W} \mathrm{~m}^{-2}$ averaged over the whole earth. The TSI that TIM measures is $\sim 6 \mathrm{~W} \mathrm{~m}^{-2}$ lower than the canonical value of $1367 \mathrm{~W} \mathrm{~m}^{-2}$ that many climate models presently use (Kopp and Lean 2011) and some $15 \mathrm{~W} \mathrm{~m}^{-2}$ less than initial space-based measurement, made by the Nimbus-7 spacecraft, of $1376 \mathrm{~W} \mathrm{~m}^{-2}$ (Hickey et al. 1980). Extensive laboratory calibration and assessment establish the lowest of these values as the most accurate and most likely absolute value of total solar irradiance.

Reducing total solar irradiance by $6 \mathrm{~W} \mathrm{~m}^{-2}(\sim 0.4 \%)$ reduces incoming solar energy by $1.5 \mathrm{~W} \mathrm{~m}^{-2}$ (the irradiance spread over the surface of the earth) and absorbed solar radiation by a little over $1 \mathrm{~W} \mathrm{~m}^{-2}$ (assuming 
a) Surface Air Temperature $\left(13671 \times \mathrm{CO}_{2}\right)$
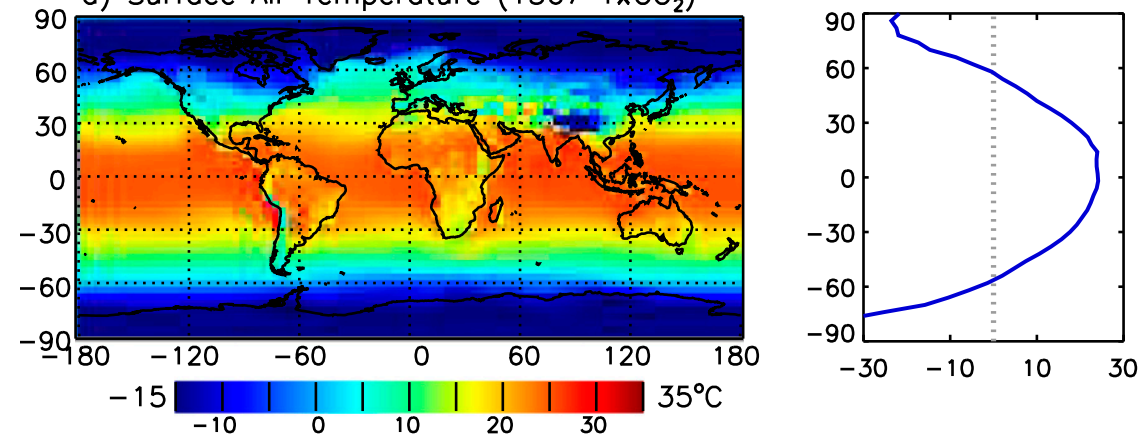

b) Surface Air Temperature $\left(13611 \times \mathrm{CO}_{2}\right)$
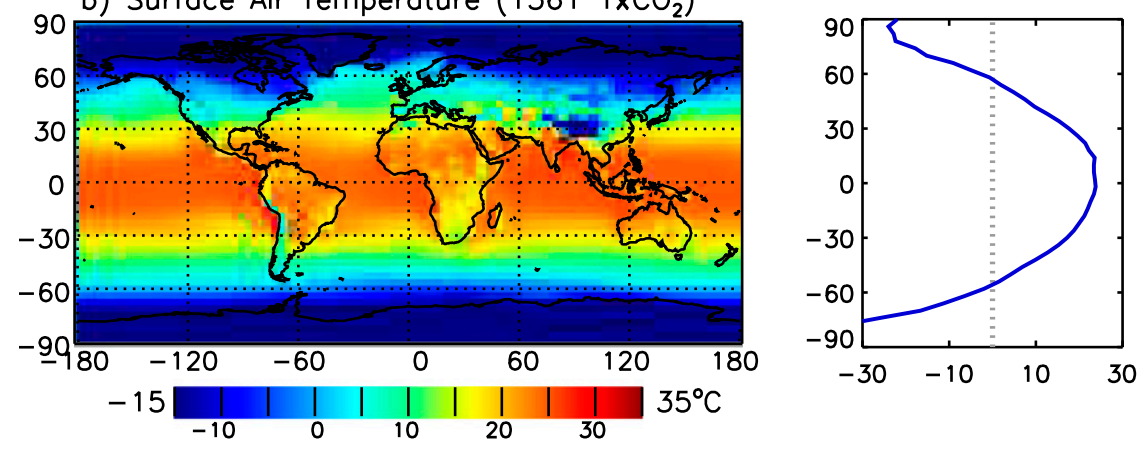

c) Change (1361-1367)
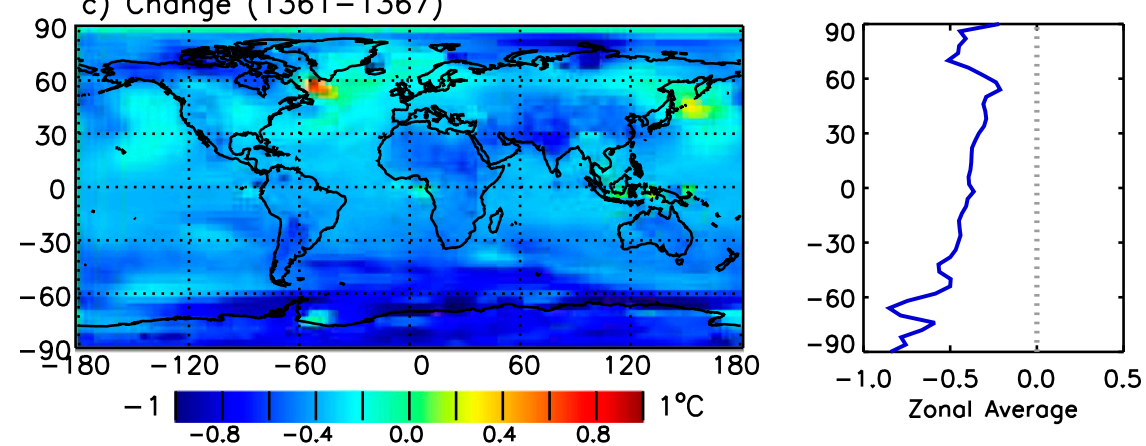

FIG. 1. Surface air temperature averaged over years 101-500 of the Model 3 simulations is shown for the preindustrial climate using a total solar irradiance value (a) of $1367.0 \mathrm{~W} \mathrm{~m}^{-2}$ and (b) of $1361.3 \mathrm{~W} \mathrm{~m}^{-2}$. (c) The climate change resulting from this change in solar irradiance. In contrast to the results in the rest of this paper, no calibration was performed to ensure radiation balance in Model 3 when using the lower solar irradiance value.

a global planetary albedo of $30 \%$ ). This uncertainty in the solar irradiance value produces an equivalent uncertainty in the earth's energy balance (the difference between incoming and outgoing radiation) that is larger in magnitude than the earth's current energy imbalance, which climate models estimate to be less than $1 \mathrm{~W} \mathrm{~m}^{-2}$ (Loeb et al. 2012). An imbalance in the earth's presentday incoming (solar) and outgoing (terrestrial) energy is a harbinger of unrealized climate forcing that may contribute to future climate change.

We investigate the difference that using the new lower absolute value of total solar irradiance makes in general circulation model climate simulations, such as those used in the Intergovernmental Panel on Climate Change (IPCC) reports. Were the sun's total solar irradiance to actually change by $6 \mathrm{~W} \mathrm{~m}^{-2}$, the resultant climate forcing of $\sim 1 \mathrm{~W} \mathrm{~m}^{-2}$ [assuming climate sensitivity of $0.7^{\circ} \mathrm{C}\left(\mathrm{W} \mathrm{m}^{-2}\right)^{-1}$ forcing] would be comparable to the forcing by increasing $\mathrm{CO}_{2}$ concentrations in the industrial era since 1850 (about $60 \%$ of the estimated greenhouse gas forcing). The temperature change that such a decrease induces is highly significant, with a global value of $-0.43^{\circ} \mathrm{C}$ and regional changes shown in Fig. 1. Coincidentally, such changes are of similar magnitude to the climate response simulated for prescribed solar irradiance change from the Maunder Minimum of anomalously low solar activity 
to the present (e.g., Rind et al. 2004). However, the reduction of $6 \mathrm{~W} \mathrm{~m}^{-2}$ does not represent a change over time. Rather, it is a more accurate estimate of the TSI absolute value; the change with time that has been measured during the 11-yr solar cycle is a factor of 5 smaller, of order $1 \mathrm{~W} \mathrm{~m}^{-2}$. The investigation here, which is the first of its kind, explores the impact that uncertainty in the absolute level of solar radiation has on the current (or more precisely the preindustrial) climate and on climate change simulations.

Climate models used for simulating anthropogenic climate change are "calibrated" to ensure that the global-mean net radiation at the top of the atmosphere, and hence the net heating at the surface, is small. This radiation balance is implemented in simulations of preindustrial climate against which climate forced scenarios are then referenced. In the absence of such a calibration, the model's energy imbalance forces ocean temperatures to depart from observed conditions without any climate forcing, producing spurious climate trends. Individual climate models employ a variety of procedures to achieve this radiation balance (Solomon et al. 2007, p. 596) but most approaches involve cloud or convective parameterizations. For example, Goddard Institute for Space Studies (GISS) Model E tunes the threshold relative humidity for the initiation of ice and water clouds to achieve global radiative balance (i.e., net radiation at the TOA within $\pm 0.5 \mathrm{~W} \mathrm{~m}^{-2}$ of zero) and a reasonable planetary albedo (between $29 \%$ and $31 \%$ ) for the $1 \times \mathrm{CO}_{2}$ simulations (Schmidt et al. 2006, p. 163). It is because of this model "calibration" that differences in the absolute value of total solar irradiance that various models use are assumed not to impact their simulations of climate change.

To test this assumption, we investigate differences in climate specification and climate change that the lower, more accurate, TSI value of $1361.3 \mathrm{~W} \mathrm{~m}^{-2}$ makes relative to the higher value of $1367.0 \mathrm{~W} \mathrm{~m}^{-2}$. We simulate the preindustrial climate and a climate with doubled $\mathrm{CO}_{2}$ concentrations $\left(2 \times \mathrm{CO}_{2}\right)$ using the coupled atmosphereocean model described in the following section, as well as specified preindustrial sea surface temperatures (SSTs) and sea ice [updated from Hurrell et al. (2008) for phase 5 of the Coupled Model Intercomparison Project (CMIP5), provided by the Hadley Centre].

\section{Climate model and procedures}

The GISS Global Climate Middle Atmosphere Model 3 (Rind et al. 2007), which we refer to as Model 3, has been employed for many experiments involving increased atmospheric $\mathrm{CO}_{2}$ concentrations, solar irradiance variations (Rind et al. 2008), and paleoclimate simulations.
The model includes a full middle atmosphere (top at $\sim 85 \mathrm{~km}$ ) and is coupled to the Russell et al. (1995) ocean model, which is similar to the ocean model used in the GISS-IPCC "Er" experiments (Schmidt et al. 2006). When Model 3 is run with doubled atmospheric $\mathrm{CO}_{2}$ concentrations to equilibrium in a " $q$ flux" mode, it has a sensitivity of about $2.8^{\circ} \mathrm{C}\left[0.7^{\circ} \mathrm{C}\left(\mathrm{W} \mathrm{m}^{-2}\right)^{-1}\right]$ (note that the $q$-flux mode is not used in these experiments).

The version of Model 3 that we use here has $4^{\circ}$ latitude $\times 5^{\circ}$ longitude resolution and 23 vertical atmospheric layers. Climate simulations are made using either the dynamical ocean or specified SSTs and sea ice (for preindustrial times, 1876-85, available from the Hadley Centre at http://www.metoffice.gov.uk/hadobs/ hadsst3/). Since the model covers the full middle atmosphere, a difference in the level of solar radiation input to the model affects solar absorption at higher altitudes near the stratopause as well as in the troposphere. A linearized ozone photochemistry scheme (McLinden et al. 2000) is employed in the stratosphere to more fully assess the impact of different solar irradiance levels in this region and to calculate ozone directly, while a simplified ozone photochemical scheme adapted from the Goddard Earth Observing System chemical transport model (GEOS-Chem) results is used in the troposphere (Rind et al. 2007).

Similar to all GISS models, Model 3, like Model E, achieves approximate radiative balance (in $1 \times \mathrm{CO}_{2}$ runs, i.e., with no external climate forcing) by adjusting its parameterization of cloud formation. The GISS models, including Model 3, derive clouds via a probabilistic representation of the chance of forming a cloud compared with the relative humidity specified for the particular model gridbox and atmospheric layer (Yao and Del Genio 1999). In practice, the relative humidity is compared with a random number (from a random number generator) at each time step; a cloud is allocated to fill the grid box when its relative humidity exceeds the random number. However, while the chance of getting a cloud is much greater with a relative humidity of $90 \%$ than $10 \%$, there is no certainty in either case. When a cloud is deemed present, it is presumed to occupy $100 \%$ of the grid box for that atmospheric level; otherwise, there is $0 \%$ cloud cover in that level. On a monthly average, this full cloud cover in each grid box occurring part of the time produces a similar radiative response to calculating partial cloud cover in the grid box all of the time (A. Lacis 2013, personal communication), for which the random number could also have been used.

In Model 3, the tuning parameter of choice for investigating the impact of different solar irradiance values is the initial relative humidity at which the calculation is begun. Since even a $10 \%$ relative humidity occasionally 
produces a cloud with this scheme, the lower the relative humidity at which the procedure is initiated, the greater the cloud cover. Observations do not indicate with any great precision what the relationship between relative humidity and cloud formation should be, and it is likely to be situation dependent. Nevertheless, this approach produces the broad representation of cloud cover seen in various datasets (e.g., Schmidt et al. 2006). As noted above, from Schmidt et al., the procedure is not entirely without an overall constraint as observations do indicate that the model planetary albedo should be $\sim 30 \%$.

Clouds can have both positive and negative effects on the earth's radiation balance, but in general the greater the cloud cover the larger the atmospheric and planetary albedos, the smaller the solar energy present in the climate system. This is evident in both observations [e.g., Kiehl and Trenberth (1997), who found clouds produce a net cooling of $-20 \mathrm{~W} \mathrm{~m}^{-2}$ ] and models [Solomon et al. (2007, p. 768$)$ where the global annual mean effect of cloud cover averaged over all models for 1980-99 is $-22.3 \mathrm{~W} \mathrm{~m}^{-2}$ ]. Thus, in the Model 3 simulations, changing the incoming absolute solar irradiance value requires that the initial relative humidity for starting the cloud calculation also be changed to maintain radiative balance. Specifically, when substituting a total solar irradiance value of 1361.3 for $1367.0 \mathrm{~W} \mathrm{~m}^{-2}$ the initial relative humidity is raised from $82.7 \%$ to $83.1 \%$, which reduces the global cloud cover from $58.3 \%$ to $57.8 \%$ and admits more solar radiation to the earth system, thereby compensating for reducing the incident energy value spread over the earth from 341.8 to $340.4 \mathrm{~W} \mathrm{~m}^{-2}$. In the simulations made using specified sea surface temperatures and sea ice for the two solar irradiance values, the compensatory initial relative humidity for cloud formation changed from $81.45 \%$ for TSI $=1367.0$ to $81.97 \%$ for TSI $=1361.3$.

Changing the cloud cover in a climate model affects multiple aspects of the climate system and potentially impacts climate sensitivity as well. Furthermore, achieving a new radiation balance on a global basis does not necessarily preclude local radiation imbalances, which may well differ for different amounts of incoming solar radiant energy; for example, in regions where cloud cover is absent in either case, higher incident solar radiation deposits more energy at the surface. To assess the consequences of different levels of incident solar radiation, we performed a suite of experiments, summarized in Table 1, with two different values of TSI each for two different levels of atmospheric $\mathrm{CO}_{2}$ concentrations, corresponding to preindustrial $(270 \mathrm{ppm})$ and doubled $\mathrm{CO}_{2}(540 \mathrm{ppm})$ conditions.

Radiation balance is achieved as described above for each of the four simulations identified as runs 1 and 2 (made with a dynamic ocean) and runs $1 \mathrm{~S}$ and $2 \mathrm{~S}$ (made
TABLE 1. Input parameters and GISS Model 3 configurations used for simulations of the preindustrial and doubled $\mathrm{CO}_{2}$ climates, using two different absolute values of total solar irradiance.

\begin{tabular}{lcll}
\hline \hline Run & $\begin{array}{c}\text { Solar irradiance } \\
\left(\mathrm{W} \mathrm{m}^{-2}\right)\end{array}$ & Atmosphere & \multicolumn{1}{c}{ Ocean } \\
\hline 1 & 1367.0 & preindustrial $1 \times \mathrm{CO}_{2}$ & $\begin{array}{l}\text { coupled dynamic } \\
\text { specified } \\
1 \mathrm{~S}\end{array}$ \\
2 & 1361.3 & preindustrial $1 \times \mathrm{CO}_{2}$ & $\begin{array}{l}\text { coupled dynamic } \\
\text { specified } \\
\text { coupled dynamic }\end{array}$ \\
$2 \mathrm{~S}$ & & & \\
$2 \mathrm{oz}$ & $\Delta \mathrm{UV}$ does not \\
affect $\mathrm{O}_{3}$ & & anthropogenic $2 \times \mathrm{CO}_{2}$ & $\begin{array}{l}\text { coupled dynamic } \\
\text { specified } \\
\text { coupled dynamic } \\
\text { specified }\end{array}$ \\
3 & 1367.0 & anthropogenic $2 \times \mathrm{CO}_{2}$ & \\
$3 \mathrm{~S}$ & 1361.3 & & \\
$4 \mathrm{~S}$ & & &
\end{tabular}

with specified sea surface temperatures), in Table 1, by adjusting the cloud formation probability to make the net radiation at the top of the atmosphere and at the surface approximately zero. We then assess (section 3 ) the model outputs to determine whether the simulations made with two different absolute solar irradiance values and their corresponding cloud coverage differ noticeably in their specification of the present-day climate (recognizing that differences between the preindustrial and current climate atmospheric conditions will exist with both irradiance values). If so, are these differences associated with atmosphere-ocean interactions (runs 1 and 2), or do they exist even with the same (specified) preindustrial sea surface temperatures (runs $1 \mathrm{~S}$ and $2 \mathrm{~S}$ )? In section 4, we investigate whether the different model configurations associated with the two different solar irradiance values produce different climate sensitivities or change any characteristics of the climate system simulated with doubled levels of $\mathrm{CO}_{2}$ (runs 3 and 4). We also assess how much of the differences are associated with the atmosphere-ocean interaction versus the atmosphereland response alone (runs $3 \mathrm{~S}$ and $4 \mathrm{~S}$ ) by using the same specified SSTs and sea ice in each run, obtained from the last 100 years of run 3 .

All Model 3 simulations made using the coupled dynamical ocean, both for preindustrial $(270 \mathrm{ppm})$ and doubled (540 ppm) $\mathrm{CO}_{2}$ concentrations (runs 1, 2, 3, and 4 in Table 1), were extended for 500 years. Although this time is insufficient to achieve true equilibrium, the atmospheric climate parameters are relatively stable long before 500 years; the results given in Table 2 are averages over model simulation years $100-500$. The changes from these numbers for averages of just the last 100 years are shown in parenthesis, and they indicate little difference from the 400-yr averaging, emphasizing the stability of the results. Because the specified SST runs (1S, 2S, 3S, and 4S) have much less variability or trend, 
TABLE 2. Global annual averages for years $101-500$ of the Model 3 simulations. The values in parentheses indicate the (very small) differences from the 400 -yr averages obtained when averaging over just the last 100 years.

\begin{tabular}{|c|c|c|c|c|}
\hline \multirow[b]{2}{*}{ Parameter } & \multicolumn{2}{|c|}{$1 \times \mathrm{CO}_{2}$} & \multicolumn{2}{|c|}{$2 \times \mathrm{CO}_{2}$} \\
\hline & $\begin{array}{l}\text { TSI } 1367.0 \\
\text { Run } 1\end{array}$ & $\begin{array}{l}\text { TSI } 1361.3 \\
\text { Run } 2\end{array}$ & $\begin{array}{l}\text { TSI } 1367.0 \\
\text { Run } 3\end{array}$ & $\begin{array}{l}\text { TSI } 1361.3 \\
\text { Run } 4\end{array}$ \\
\hline Incoming SW $\left(\mathrm{W} \mathrm{m}^{-2}\right)$ & $341.8(0)$ & $340.4(0)$ & $341.8(0)$ & $340.4(0)$ \\
\hline Planetary albedo (\%) & $30.92(+.05)$ & $30.71(+.06)$ & $30.50(+.02)$ & $30.27(0.02)$ \\
\hline Ground albedo (\%) & $14.03(+.11)$ & $14.08(+.11)$ & $13.21(-0.01)$ & $13.23(-0.02)$ \\
\hline SW absolute below model top $\left(\mathrm{W} \mathrm{m}^{-2}\right)$ & $236.1(-0.01)$ & $235.9(-0.02)$ & $237.6(-0.1)$ & $237.4(-0.1)$ \\
\hline SW incoming at surface $\left(\mathrm{W} \mathrm{m}^{-2}\right)$ & $190.9(+.1)$ & $191.3(0)$ & $189.4(-0.2)$ & $189.7(-0.2)$ \\
\hline SW absolute at surface $\left(\mathrm{W} \mathrm{m}^{-2}\right)$ & $164.1(-0.1)$ & $164.3(-0.2)$ & $164.3(-0.1)$ & $164.6(-0.2)$ \\
\hline Net LW at model top $\left(\mathrm{W} \mathrm{m}^{-2}\right)$ & $-235.3(+.1)$ & $-235.1(+.1)$ & $-235.8(-0.3)$ & $-235.7(-0.1)$ \\
\hline $\mathrm{LW}$ incoming at surface $\left(\mathrm{W} \mathrm{m}^{-2}\right)$ & $328.5(-0.2)$ & $327.4(-0.2)$ & $343.1(-1.1)$ & $342(1)$ \\
\hline $\mathrm{LW}$ emission at surface $\left(\mathrm{W} \mathrm{m}^{-2}\right)$ & $-387.5(+.2)$ & $-386.9(+.2)$ & $-399.1(-1)$ & $-398.5(-0.8)$ \\
\hline GH efficiency (LW surface - LW top)/LW surface & $0.39(0)$ & $0.39(0)$ & $0.41(0)$ & $0.41(0)$ \\
\hline Net radiation at model top $\left(\mathrm{W} \mathrm{m}^{-2}\right)$ & $0.8(+.05)$ & $0.8(-0.1)$ & $1.7(-0.16)$ & $1.7(-0.3)$ \\
\hline Net radiation at surface $\left(\mathrm{W} \mathrm{m}^{-2}\right)$ & $105.1(-0.1)$ & $104.8(-0.1)$ & $108.3(+.1)$ & $108.1(0)$ \\
\hline Sensible heat at surface $\left(\mathrm{W} \mathrm{m}^{-2}\right)$ & $-25.8(0)$ & $-25.9(0)$ & $-24.0(+.1)$ & $-24.1(+.1)$ \\
\hline Latent heat at surface $\left(\mathrm{W} \mathrm{m}^{-2}\right)$ & $-78.4(-0.1)$ & $-78.2(0)$ & $-82.6(-0.3)$ & $-82.3(-0.4)$ \\
\hline Net heating at surface $\left(\mathrm{W} \mathrm{m}^{-2}\right)$ & $-0.04(-0.07)$ & $-0.1(-0.09)$ & $0.96(-0.26)$ & $0.90(-0.23)$ \\
\hline Surface air temperature $\left({ }^{\circ} \mathrm{C}\right)$ & $11.99(-0.05)$ & $11.85(-0.04)$ & $14.27(0.18)$ & $14.15(0.17)$ \\
\hline Atmospheric temperature $\left({ }^{\circ} \mathrm{C}\right)$ & $-25.09(-0.03)$ & $-25.24(-0.03)$ & $-23.16(0.12)$ & $-23.3(+.1)$ \\
\hline Total cloud cover $(\%)$ & $58.3(0)$ & $57.8(+.1)$ & $57.0(0)$ & $56.5(0)$ \\
\hline Low cloud cover $(\%)$ & $48.6(+.1)$ & $48.1(0.1)$ & $47(-0.1)$ & $46.4(0)$ \\
\hline Middle cloud cover $(\%)$ & $17.0(-0.5)$ & $17.0(0)$ & $16.0(+.1)$ & $16.0(-0.1)$ \\
\hline High cloud cover $(\%)$ & $19.3(0)$ & $19.2(0)$ & $20.1(+.1)$ & $20.1(+.1)$ \\
\hline Precipitation $\left(\mathrm{mm} \mathrm{day}^{-1}\right)$ & $2.71(0)$ & $2.70(0)$ & $2.85(+.02)$ & $2.85(+.01)$ \\
\hline $\mathrm{H}_{2} \mathrm{O}$ of atmosphere $(\mathrm{mm})$ & $21.4(-0.1)$ & $21.2(-0.1)$ & $25.2(+.2)$ & $24.9(+.2)$ \\
\hline Snow cover $(\%)$ & $13.8(+.1)$ & $14.0(+.1)$ & $11.9(-0.1)$ & $12.0(-0.1)$ \\
\hline Sea ice cover $(\%)$ & $5.7(+.2)$ & $5.8(+.2)$ & $4.6(0)$ & $4.6(0)$ \\
\hline Total earth water $\left(\mathrm{kg} \mathrm{m}^{-2}\right)$ & $464.7(+.4)$ & $461.3(0.2)$ & $461(-0.2)$ & $456.7(0)$ \\
\hline Total ozone (DU) & $354(0.1)$ & $352.7(0)$ & $360.8(-0.6)$ & $359.6(-0.5)$ \\
\hline
\end{tabular}

simulations were made for 200 years, with results pertaining to the last 100 years.

As noted above, the model configuration includes ozone calculations in the stratosphere, so reducing the solar irradiance value also reduces the ultraviolet (UV) portion of the spectrum that affects ozone. Since not all climate models incorporate online chemistry calculations, often using prescribed ozone instead, this portion of the "adjustment" to solar irradiance may not always be applicable. To test its impact, additional 500-yr runs with the lower solar irradiance value were made without altering the UV irradiance for the ozone calculation (run 2oz). Most of the tropospheric responses were comparable but, as expected, significant stratospheric consequences arose and are described.

\section{Preindustrial simulations}

Listed in Table 2 are global annual diagnostics from the Model 3 runs made using the dynamic ocean. The first two columns correspond to the preindustrial $(1 \times$ $\mathrm{CO}_{2}$ ) simulations using, respectively, the standard GISS model solar irradiance value of $1367.0 \mathrm{~W} \mathrm{~m}^{-2}$, run 1 (column 1), and an alternate value of $1361.3 \mathrm{~W} \mathrm{~m}^{-2}$, run 2 (column 2), indicative of the SORCE lower value, which is the more probable true level of the sun's irradiance. Results are 400-yr averages (from year 101 to 500) and, in parenthesis, the difference of the 400-yr average from the average over only the last $100 \mathrm{yr}$; that the differences are quite small indicates that the models were in equilibrium over the 400 -yr time frame. In the simulations made with the lower solar irradiance value (column 2), the low-level cloud cover is $48.1 \%$, reduced from $48.6 \%$, and the planetary albedo is 30.71 , reduced from 30.92 . Owing to this compensating change, the net radiation at the top of the atmosphere, and the net heat at the surface, differ by less than $0.1 \mathrm{~W} \mathrm{~m}^{-2}$ when using the lower solar irradiance value, with incoming and outgoing radiation amounts that differ by $0.2-0.3 \mathrm{~W} \mathrm{~m}^{-2}$. The global, annual average surface air temperature and integrated atmospheric temperatures are about $0.1^{\circ} \mathrm{C}$ cooler in the run with the lower solar irradiance, and there is a corresponding small reduction in the water value amount in the atmosphere, as well as a slight increase in snow cover. Despite cloud cover differences, the greenhouse efficiency of the atmosphere is essentially 


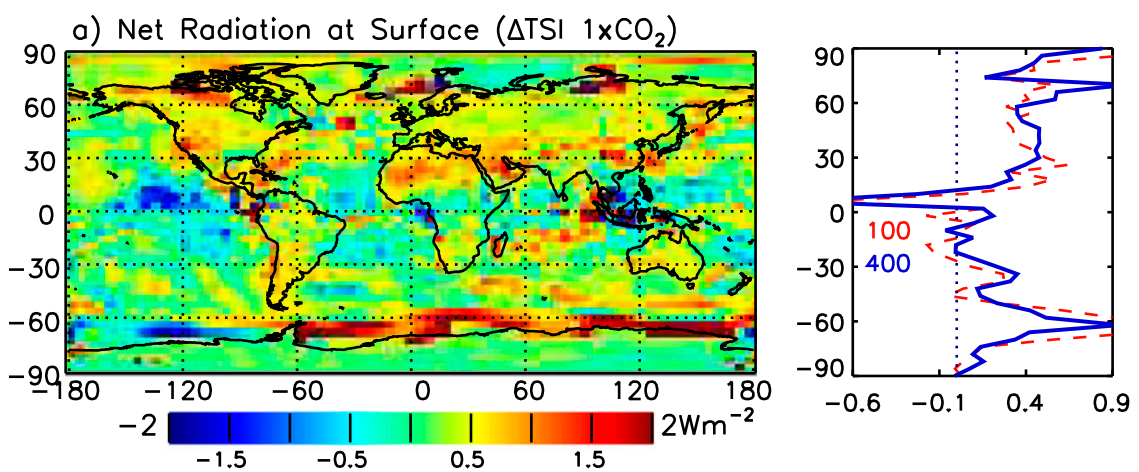

b) Total Cloud Cover $\left(\triangle \mathrm{TSI} 1 \times \mathrm{CO}_{2}\right)$
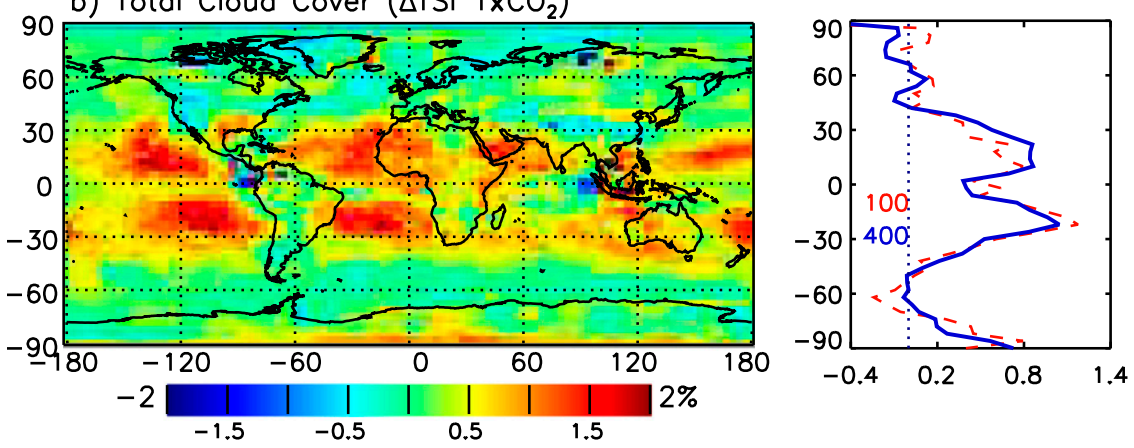

c) Planetary Albedo $\left(\Delta \mathrm{TSI} 1 \times \mathrm{CO}_{2}\right)$
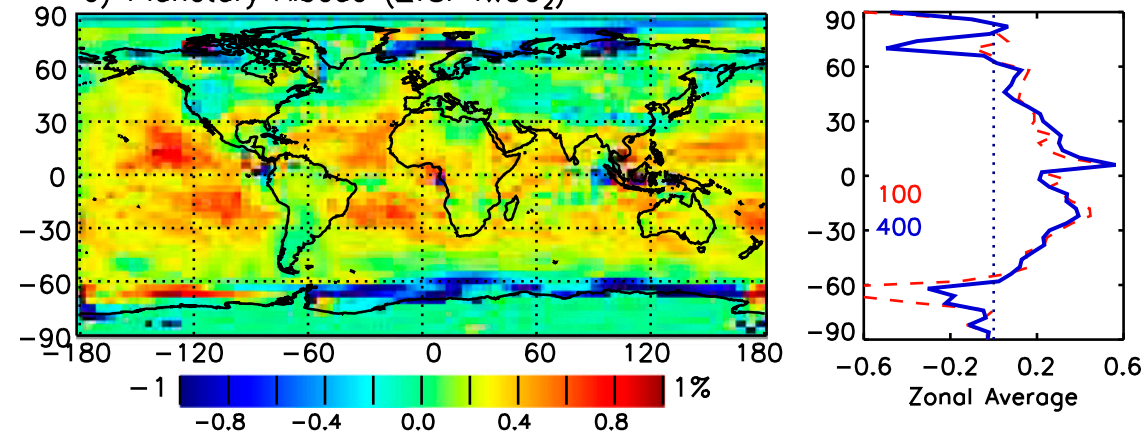

FIG. 2. Differences in annual energy budget parameters in the Model 3 simulation of the preindustrial climate using TSI $=1367.0 \mathrm{~W} \mathrm{~m}^{-2}$ minus that using TSI $=1361.3 \mathrm{~W} \mathrm{~m}^{-2}$ (run $1-$ run 2), after tuning the model to achieve zero net energy balance for each of the two different solar irradiance values with a preindustrial atmosphere. Shown are the years 101-500 average differences in (a) net surface radiation, (b) total cloud cover, and (c) planetary albedo. Zonal average differences are shown on the right, for averages of years 100-500 (solid line) and years 400-500 (dashed line) of the model simulations.

unchanged. Hence, on a global basis, the cloud cover compensation largely eradicates the impact of using different solar irradiance values in the Model 3 specification of the preindustrial climate.

Differences in regional climate specified with the two different values of solar irradiance can be somewhat larger than the global differences even with the Model 3 radiation budget parameters nominally calibrated to have zero difference globally. Shown in Fig. 2 are 400-yr annual-averaged differences determined as run 1 (higher solar irradiance) minus run 2 (lower solar irradiance) for net radiation at the surface (Fig. 2a), total cloud cover (Fig. 2b), and planetary albedo (Fig. 2c). Also shown on the right side of the figures are the zonal averages of these differences, for both the last $100 \mathrm{yr}$ (model years 401-500, dashed line) and $400 \mathrm{yr}$ (model years 101-500, solid line) of the simulations. The net radiation at the surface (Fig. 2a) is of mixed sign, with a tendency for greater radiation at the surface at high latitudes and less in the tropics. This is a direct result of the different cloud cover parameterizations (Fig. 2b) with total (and low) cloud cover a few percent higher (in absolute terms) in 

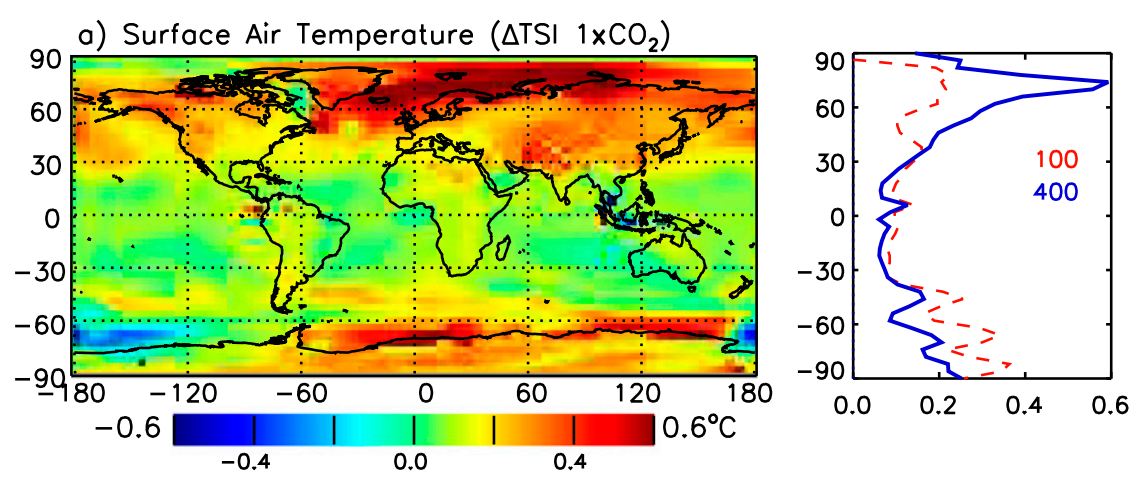

b) Sea Level Pressure $\left(\triangle \mathrm{TS} \mid 1 \times \mathrm{CO}_{2}\right)$
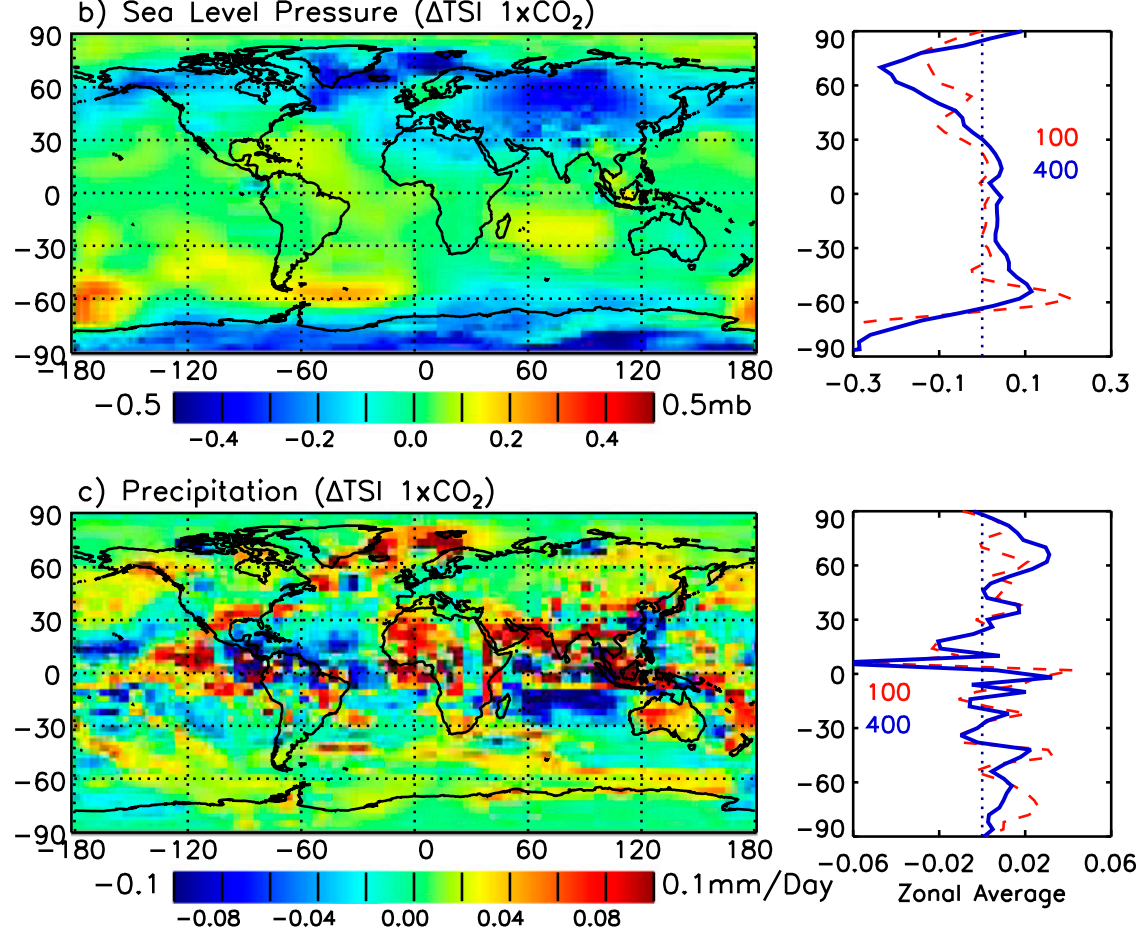

FIG. 3. As in Fig. 2, but in annual climate parameters for (a) the surface air temperature, (b) sea level pressure, and (c) precipitation.

the tropics when using the higher solar irradiance value. The surface energy differences also affect the sea ice distribution with notably less sea ice around most of Antarctica associated with the greater positive surface radiation that accompanies the higher absolute value of solar irradiance. The planetary albedo differences (Fig. 2c) reflect the cloud and surface responses, with reductions of up to $1 \%$ (absolute) where sea ice and clouds are both diminished and increases of up to $1 \%$ where tropical cloud cover has increased.

Unfortunately, cloud cover observations are not sufficiently constrained for us to assess whether the differences necessitated by altering cloud cover to accommodate the reduced solar insolation makes Model 3 more or less accurate in that respect. The differences shown in Fig. 2 are of order $1 \%$, and International Satellite Cloud Climatology Project cloud observations on a monthly average are accurate to only 3\% (http://isccp.giss.nasa.gov/ index.html). Similarly, the difference in net radiation at the surface is less than $2 \mathrm{~W} \mathrm{~m}^{-2}$, while ISCCP errors are $\sim 15 \mathrm{~W} \mathrm{~m}^{-2}$. The following section provides additional comparisons with other observations.

Regional impacts of different TSI values are also evident in other Model 3 climate parameters, which Fig. 3 illustrates. Shown are the differences in surface air temperature (Fig. 3a), sea level pressure (Fig. 3b), and precipitation (Fig. 3c), which are similarly determined as run 1 (higher solar irradiance) minus run 2 (lower solar irradiance). Sea level pressure is less at higher latitudes where the air has been made less stable owing to more 

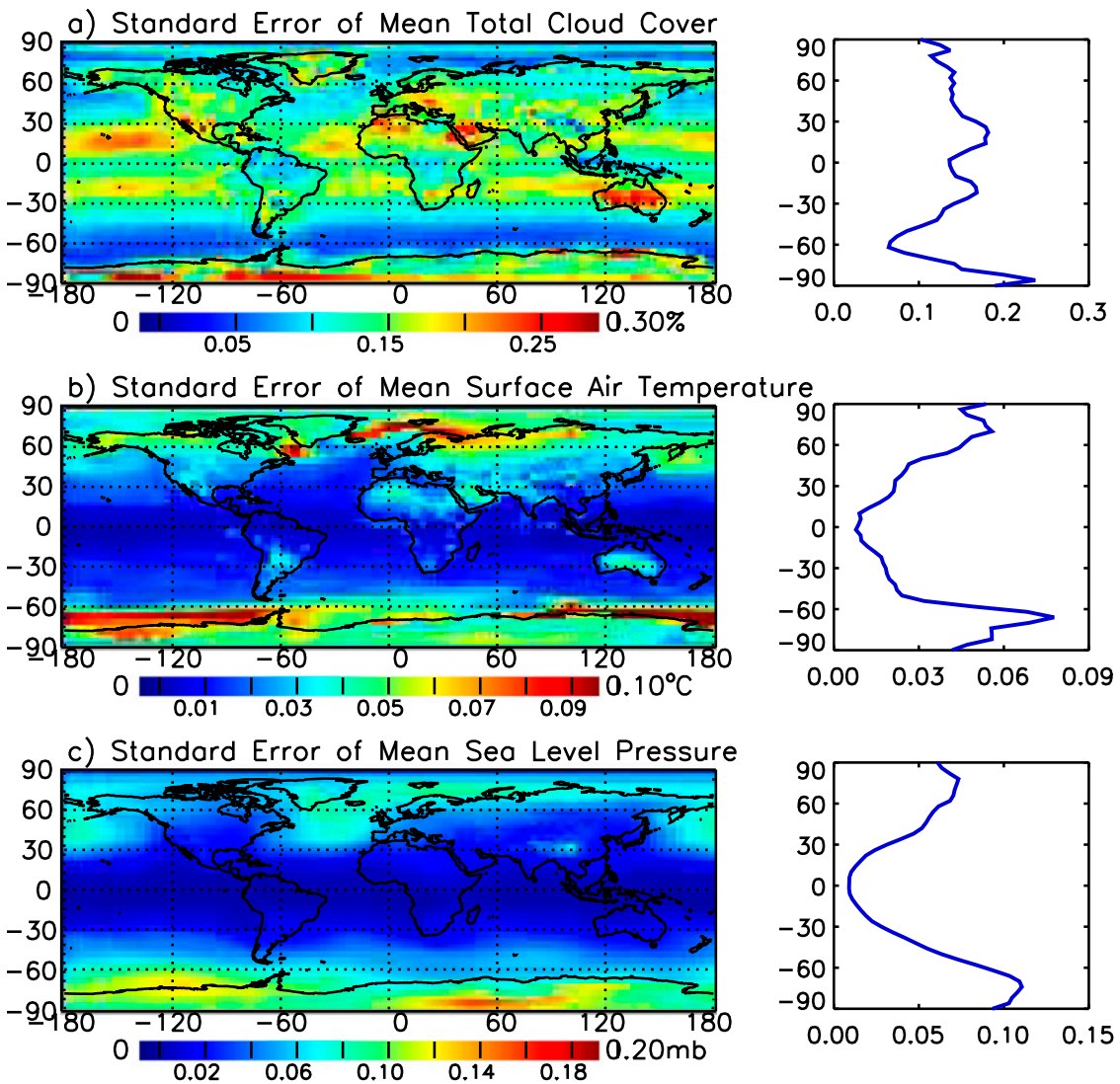

d) Standard Error of Mean Precipitation
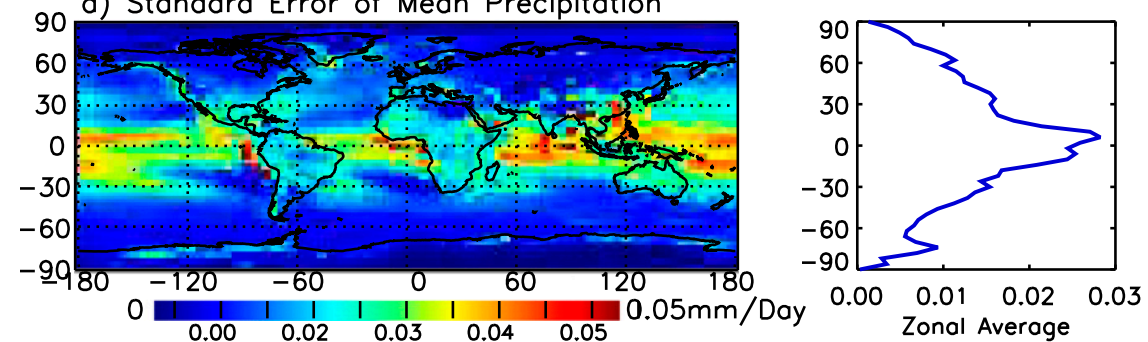

FIG. 4. Standard errors in the mean value of 400 years of the Model 3 simulations of the preindustrial climate, run 1 , determined as $\sigma$ (the standard deviation) $/ \sqrt{ } 400$ for (a) total cloud cover, (b) surface air temperature, (c) sea level pressure, (d) and precipitation. Zonal averages are shown on the right.

surface radiative forcing and greater surface air temperature, with minimal differences in the tropics. Many of the temperature differences arise from advective changes associated with altered wind flow due to the sea level pressure response. Higher temperatures also occur in the regions of sea ice reduction, especially around Antarctica.

In addition to these latitudinal differences, when using the higher solar irradiance value there is also a general tendency for Model 3 to preferentially reduce precipitation over the oceans and increase it over land, as evident in Fig. 3c (the ratio of precipitation over land to that over the ocean grows by about $1 \%$ ). Certain land regions have little cloud cover to begin with, and thus the reduced cloud cover needed to calibrate the model for the lower values of solar irradiance has little effect. Without altered cloud cover the net radiation at the surface (driven by net solar radiation at the top of the atmosphere) tends to be larger when using the higher absolute solar irradiance value (e.g., the Sahara, Fig. 2a). This leads to relative ascent over land with corresponding subsidence over the ocean and consequent precipitation anomalies. The significance of each of these differences is discussed below in comparison with the standard errors in the mean values of the $1 \times \mathrm{CO}_{2}$ run (run 1 ), which are shown in Fig. 4. 

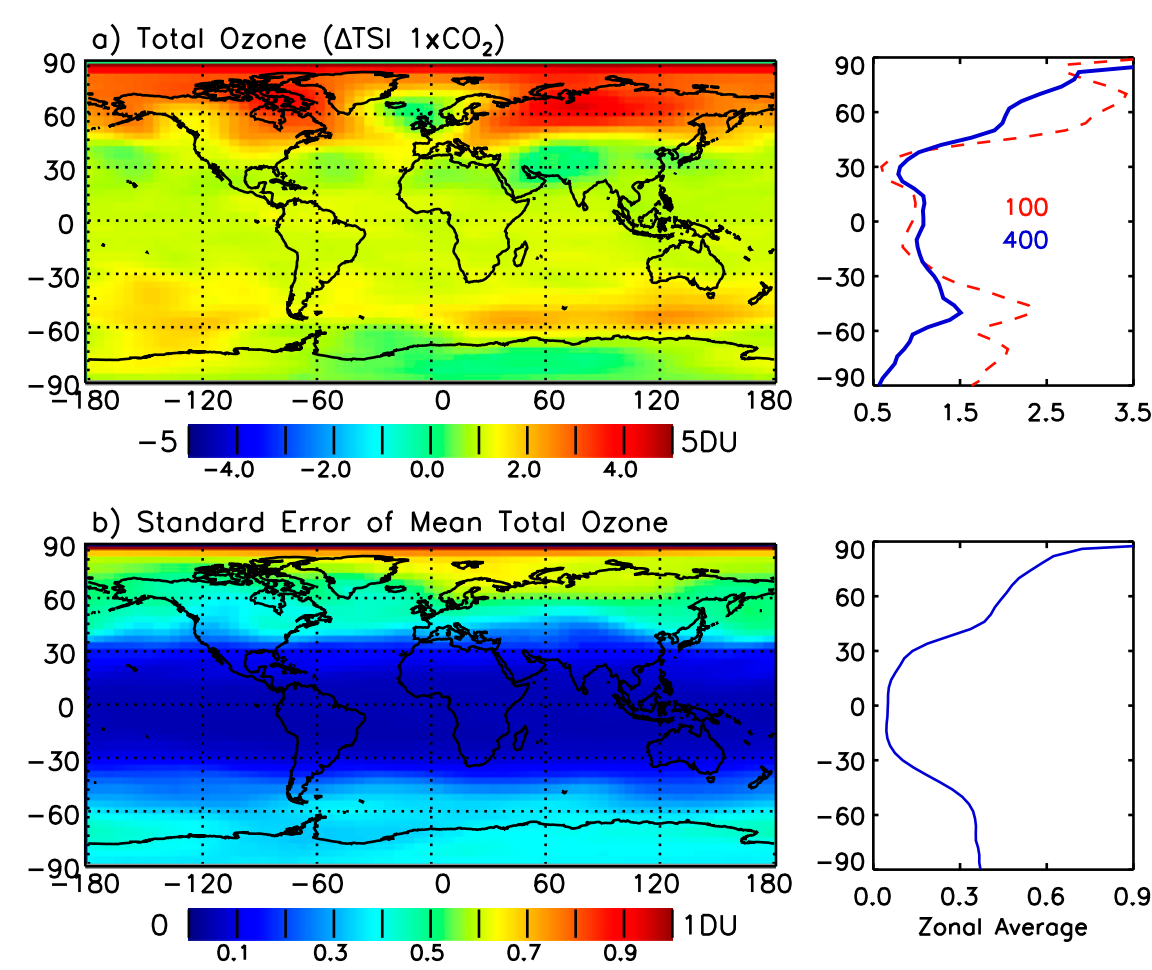

FIG. 5. (a) Differences in Model 3 simulations of annual total ozone in the preindustrial climate using two different absolute values of solar irradiance, the year 101-500 average differences of run 1 - run 2. (b) The standard error in the mean ozone value from run 1 . Zonal averages are shown on the right.

Different levels of solar irradiance also affect the Model 3 stratospheric parameters, including the ozone distribution, especially at high northern latitudes. Figure 5 shows differences in total ozone when using two different absolute values of total solar irradiance (Fig. 5a) and the standard error in the mean values (Fig. 5b). Most notable is an overestimation of a few Dobson units (DU) in the total column ozone at high northern latitudes when using the higher solar irradiance value, a difference that is about five times larger than the standard error in the model's mean values. In general, with the higher value of total solar irradiance, Model 3 produces larger atmospheric temperatures at all levels in the troposphere and stratosphere, of order $0.15^{\circ} \mathrm{C}$ relative to the lower irradiance level. Figure 6a shows the differences in the vertical profile of the zonally averaged temperature. The simulated warmer conditions by themselves lead to a reduction of ozone concentrations in general $(0.03 \%$ DU decrease) in the experiment in which UV spectral irradiance remained unchanged (run 2oz), as shown in Fig. 6b. However, when the UV irradiance is also reduced, consistent with SORCE's overall lower total solar irradiance value, using the higher solar (and UV) irradiance produces higher ozone levels at most locations in the stratosphere by 1.3 DU overall
(Table 1), because of larger (by $0.5 \%$ ) photochemical production. Figure $6 \mathrm{c}$ shows the corresponding differences at different altitudes. Poleward transport is also overestimated (by $0.5 \%-1 \%$ ) in both hemispheres, primarily associated with the increased atmospheric loading. Figure $6 \mathrm{~d}$ shows that these dynamical differences are larger and located farther poleward in the Northern Hemisphere than in the Southern Hemisphere, as evident in the resultant distribution (Fig. 5a). The result of the overestimated temperature, photochemistry, and dynamics is an overestimate by some 4 Dobson units (1\%) of the total column ozone at high northern latitudes when using the higher solar irradiance value.

Most of the climate specification differences depicted above, while understandable (and reproducible in the simulations with no solar UV spectrum changes for ozone photochemistry), are small. Differences in global annual averages are not statistically significant by comparison with the standard deviations of the model runs. Therefore, the procedure by which net radiation balance is assured with the differing solar irradiance values proves to be sufficient to minimize differences in the Model 3 global annual-average simulations of preindustrial climate, at least from the perspective of the model's inherent variability. 

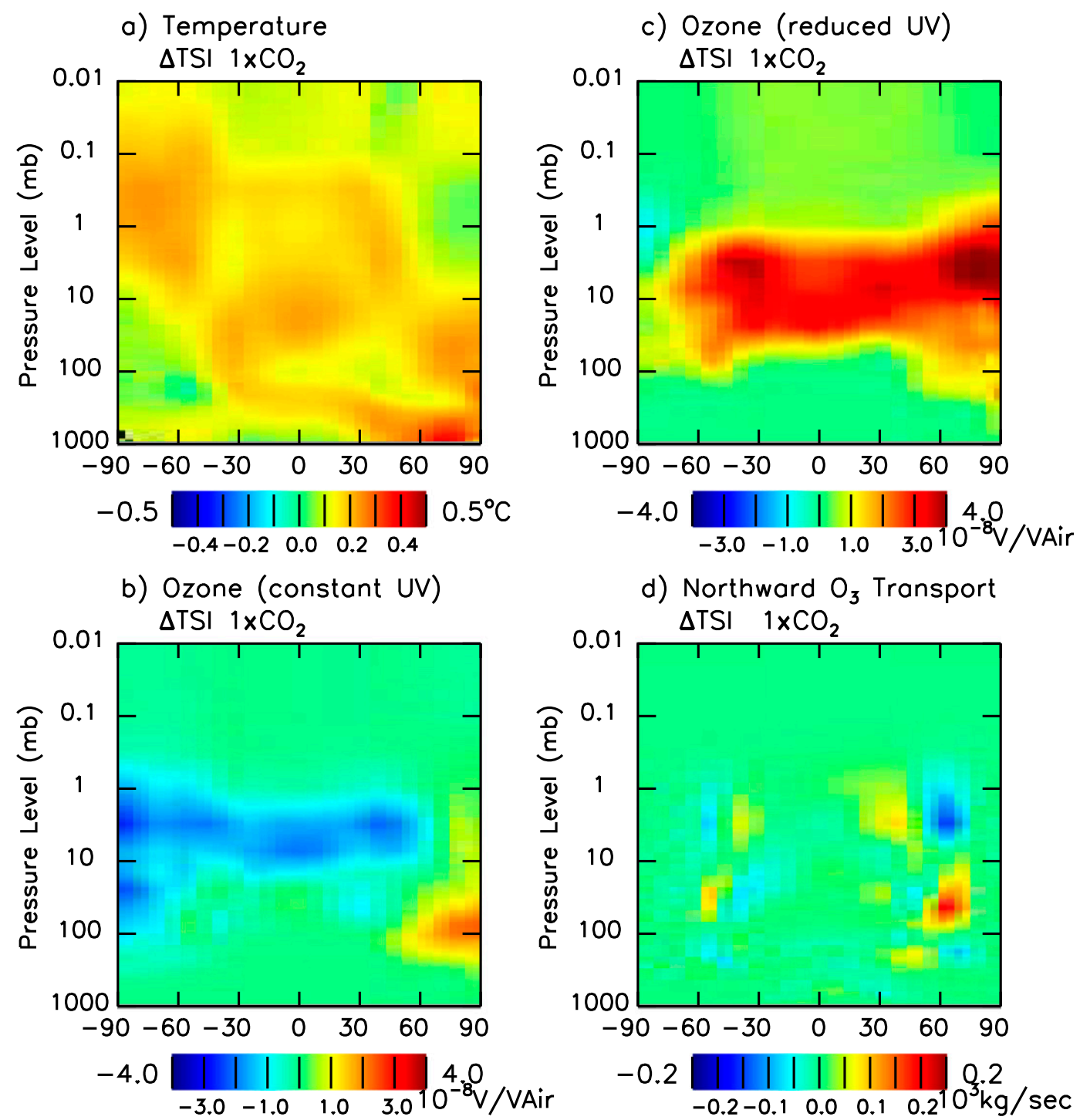

FIG. 6. Zonal average altitude profiles of differences between Model 3 simulations of the preindustrial climate using two different solar irradiance values, run 1 - run 2. Shown are the year 101-500 average differences of (a) temperature, (b) ozone with the UV change not allowed to affect ozone photochemistry, (c) ozone with the UV change allowed to affect ozone photochemistry, and (d) northward transport of ozone.

In specific regions the differences can, however, reach significant levels, even though compensating tendencies minimize the global average changes. Figure 4 shows the regional distribution of the standard error (the standard deviation divided by the square root of the sample size) in run 1 (for simulation years 100-500) for total clouds (Fig. 4a), surface air temperature (Fig. 4b), sea level pressure (Fig. 4c), precipitation (Fig. 4d), and total ozone (Fig. 5b). These indicate the Model 3 inherent variability. Differences in the radiation budget and climate parameters shown in Figs. 1 and 2 for two different solar irradiance values are significant at the $95 \%$ level when they are larger than twice the standard error of their $1 \times \mathrm{CO}_{2}$ simulations shown in Fig. 4. This is true for tropical cloud cover differences (Fig. 2b compared with Fig. 4a), high-latitude surface air temperature differences (Fig. 3a compared with Fig. 4b), and sea level pressure differences (Fig. 3b compared with Fig. 4c). Regional precipitation differences are comparable to, or only marginally larger than, the standard error in the $1 \times \mathrm{CO}_{2}$ run (Fig. $3 \mathrm{c}$ compared with Fig. 4d). The impact of using different input solar irradiance values is especially evident on the Model 3 specification of total ozone, where high-latitude differences on the order of 4 DU (Fig. 5a) exceed, by a factor of 5 or more, the standard error (Fig. 5b). 
TABLE 3. Comparison of Model 3 climate simulations with observations at the gridbox level. Listed are the averages (and in parentheses the standard deviations) of the mean, root-mean-square difference, and serial correlation coefficient of the simulations and selected observational datasets.

\begin{tabular}{|c|c|c|c|c|}
\hline Metric & $\begin{array}{l}\text { TSI } 1367.0 \\
\text { Run } 1\end{array}$ & $\begin{array}{l}\text { TSI } 1361.3 \\
\text { Run } 2\end{array}$ & $\begin{array}{c}\text { TSI } 1367.0 \\
\text { Specified SSTs } \\
\text { Run 1S }\end{array}$ & $\begin{array}{c}\text { TSI } 1361.3 \\
\text { Specified SSTs } \\
\text { Run 2S }\end{array}$ \\
\hline & \multicolumn{4}{|c|}{ Temperature } \\
\hline Mean & $-2.14(0.36)$ & $-2.27(0.35)$ & $1.22(0.44)$ & $1.26(0.42)$ \\
\hline RMS & $3.70(0.59)$ & $3.79(0.59)$ & $2.93(0.76)$ & $2.94(0.76)$ \\
\hline \multirow[t]{2}{*}{ SCC } & $0.975(0.008)$ & $0.975(0.008)$ & $0.98(0.009)$ & $0.98(0.009)$ \\
\hline & \multicolumn{4}{|c|}{ Precipitation } \\
\hline Mean & $0.05(0.47)$ & $0.03(0.46)$ & $-0.002(0.33)$ & $-0.002(0.33)$ \\
\hline RMS & $1.74(0.23)$ & $1.73(0.24)$ & $1.60(0.17)$ & $1.61(0.17)$ \\
\hline \multirow[t]{2}{*}{$\mathrm{SCC}$} & $0.645(0.013)$ & $0.648(0.014)$ & $0.751(0.02)$ & $0.748(0.02)$ \\
\hline & \multicolumn{4}{|c|}{ Sea level pressure } \\
\hline Mean & 0.08 & 0.10 & 0.03 & -0.02 \\
\hline RMS & 4.69 & 4.73 & 4.69 & 4.72 \\
\hline $\mathrm{SCC}$ & 0.842 & 0.842 & 0.847 & 0.842 \\
\hline
\end{tabular}

Most climate models utilize specified SSTs at some point in their development, to shorten the simulation time when investigating different approaches to atmospheric physics and numerical parameterizations. SSTs are also specified when calibrating parameterizations to produce near-zero net radiation balance for the current climate (e.g., Schmidt et al. 2006). So the impact that a change in total solar irradiance has on that configuration is also of interest. With the additional simulations designated runs $1 \mathrm{~S}, 2 \mathrm{~S}, 3 \mathrm{~S}$, and $4 \mathrm{~S}$ in Table 1 , we investigate what proportion of the differences results from the interaction of the atmosphere and ocean via the coupled models compared with that generated simply by the effect of the altered solar irradiance and cloud cover on the atmosphere-land system. Runs $1 \mathrm{~S}$ and $2 \mathrm{~S}$ both used the same specified preindustrial sea surface temperatures and sea ice and were assessed similarly to the results shown in the Figs. 2, 3, and 5 (which used a dynamic ocean). These additional simulations (not shown) using specified SSTs indicate that differences in cloud cover, planetary albedo, and net radiation at the surface over the tropical oceans (Figs. 2b,c) are also present when the sea surface temperatures are specified. This suggests that these differences are independent of ocean interaction; they are actually slightly reduced in magnitude with the coupled ocean response. In contrast, differences in the vicinity of Antarctica are the result of atmosphere-ocean interactions via effects of the dynamic ocean sea ice change. Differences in surface air temperature over land for the most part occur without an ocean response, while those over the ocean (including high northern latitudes) require it. Correspondingly, differences in sea level pressure are greatly affected by the ocean thermal response over the ocean, while differences over land (including Antarctica) are similar in both sets of runs (i.e., with the dynamic ocean and with specified sea surface temperatures). Tropical precipitation differences are quite distinct in the simulations made with and without ocean feedbacks, as they are influenced by circulation changes induced by land-ocean temperature gradients. In the stratosphere the ozone differences (Fig. 5) do not feel much influence from the dynamic ocean, especially in the polar regions. We conclude, therefore, that a number of the differences induced by altered solar radiation and cloud cover maintain their characteristic nature regardless of whether the ocean responds (so would be apparent in AMIP style runs), especially away from extratropical oceanic regions.

\section{Model validation}

We compare the simulations of the preindustrial climate made using two different input total solar irradiance values with current observations. For the global average radiation parameters listed in Table 2 the differences are generally too small to provide a clear indication of preference relative to current observations. We compare in Table 3 global annual averages of three metrics, each calculated on the $4^{\circ}$ latitude $\times 5^{\circ}$ longitude gridspecifically the mean biases (mean), root-mean-square biases (RMS), and spatial correlation coefficient (SCC, calculated using the Moran coefficient) — to statistically compare the two preindustrial simulations with observations of temperature, precipitation and sea level pressure. Table 3 lists the average comparison of the Model 3 simulations with the observational datasets; the 
standard deviation of the comparison with the different datasets is given in parentheses. Four observational sets were used for surface air temperature [National Centers for Environmental Prediction (NCEP) (Kalnay et al. 1996), Shea (1986), Legates and Willmott (1990), and University of East Anglia (UEA) (Jones et al. 2012)], five sets for precipitation [German Climate Research Program (DEKLIM) (Beck et al. 2005), Shea (1986), Global Precipitation Climatology Project (GPCP) (Huffman et al. 1997), Legates and Willmott (1990), and UEA (http://www.cru.uea.ac.uk/cru/data/precip/)], and one set for sea level pressure [40-yr European Centre for Medium-Range Weather Forecasts Re-Analysis (ERA40) (Uppala et al. 2005)]. The smaller the difference in the means and rms values and the larger the SCC, the better the model reproduction of the observations.

As the values in Table 3 indicate for all three climate parameters considered, the differences in the Model 3 simulations using different absolute solar irradiance values are very small, generally less than the standard deviations of the model's comparisons with the different observational datasets. Hence, for these parameters, as for the radiative values, the compensation approach used to adjust for the different solar radiation value that Model 3 uses produces $1 \times \mathrm{CO}_{2}$ simulations that are practically indistinguishable.

We also compare with current climate observations the simulations made using specified (preindustrial) sea surface temperatures and sea ice. As might be expected for most of the parameters listed in Table 2, differences when using total solar irradiance values of 1361.3 and $1367.0 \mathrm{~W} \mathrm{~m}^{-2}$ are even less when the SSTs are specified (which is why their radiative results are not given in Table 2). Table 3 gives the relationship to observations of these simulations made with the two solar irradiance values and compensatory change of initial relative humidity for cloud formation. As with the simulations using a dynamic ocean, there is minimal difference in the relationship to observations between the two runs made using specified sea surface temperatures. As expected, most of the comparisons improve slightly with specified SSTs (smaller mean and RMS differences, higher SCC). For example, the RMS temperature bias is reduced by $25 \%$ when specified SSTs are used. Note also that part of the error in both sets of simulations (dynamical ocean and specified SSTs) is because the comparisons pertain to simulations of preindustrial climate with current conditions; for example, when run with specified modern SSTs, the mean temperature error is only half as large and the RMS error is (further) reduced by $10 \%-$ $15 \%$. The conclusion is then the same as in the previous section: compensation for using different solar irradiance values successfully mitigates most of the effect this would have on the $1 \times \mathrm{CO}_{2}$ simulation, at least in comparison with present uncertainties in observed climate, even though some of the differences are larger than the model's inherent variability.

\section{Climate sensitivity and change}

In this section, we investigate how the two different absolute solar irradiance values and their corresponding cloud cover adjustments affect the Model 3 climate sensitivity and simulation of anthropogenic climate change. To address this, as indicated earlier, additional simulations were made (runs 3 and 4 in Table 1 ) in which the $\mathrm{CO}_{2}$ concentrations were instantaneously doubled and the model run for 500 years with the coupled ocean (the simulations were actually begun some 100 years after the $1 \times \mathrm{CO}_{2}$ run started and appeared to have stabilized). Columns 3 and 4 of Table 2 give the global annual-average results.

Considering first the $2 \times \mathrm{CO}_{2}$ experiments themselves, the differences between them directly (run 3 versus run 4) are visually very similar to the differences in the $1 \times \mathrm{CO}_{2}$ simulations (shown in Figs. 2 and 3), although at times with somewhat muted amplitude. So the bias that a different solar irradiance level introduces to the $1 \times \mathrm{CO}_{2}$ runs carries over, qualitatively at least, into the climate change simulations.

Although qualitatively quite similar, changes in climate simulated using two different absolute solar irradiance values are not identical. To understand how the value of solar radiation in the preindustrial simulations impacts climate change assessments, we compare the $2 \times \mathrm{CO}_{2}$ minus $1 \times \mathrm{CO}_{2}$ climate change for the two different solar irradiance values (i.e., we compare run 3 minus run 1 , indicative of anthropogenic climate change with the higher solar irradiance value, with run 4 minus run 2, indicate of anthropogenic climate change with the lower, more probable total irradiance value).

Both Model 3 simulations (i.e., using the two different total solar irradiance values) made with $2 \times \mathrm{CO}_{2}$ remain out of radiation balance for the duration of the runs, by $0.7 \mathrm{~W} \mathrm{~m}^{-2}$. As noted earlier, the Model 3 doubled $\mathrm{CO}_{2}$ sensitivity (when run with a $q$-flux ocean, not in these experiments) is $2.8^{\circ} \mathrm{C}$ for $\sim 4 \mathrm{~W} \mathrm{~m}^{-2}$ radiative forcing, so the imbalance would result in projected additional warming of $\sim 0.5^{\circ} \mathrm{C}$. The doubled $\mathrm{CO}_{2}$ warming with the dynamic ocean at the end of $500 \mathrm{yr}$ for the higher solar irradiance is $2.51^{\circ} \mathrm{C}$, the same as with the lower value. Hence, the compensation for the altered solar irradiance does not change climate sensitivity on a global basis.

We next consider how the patterns of climate change for doubled $\mathrm{CO}_{2}$ concentrations differ. Shown in the top panels of Figs. 7-11 are the changes in total cloud cover 

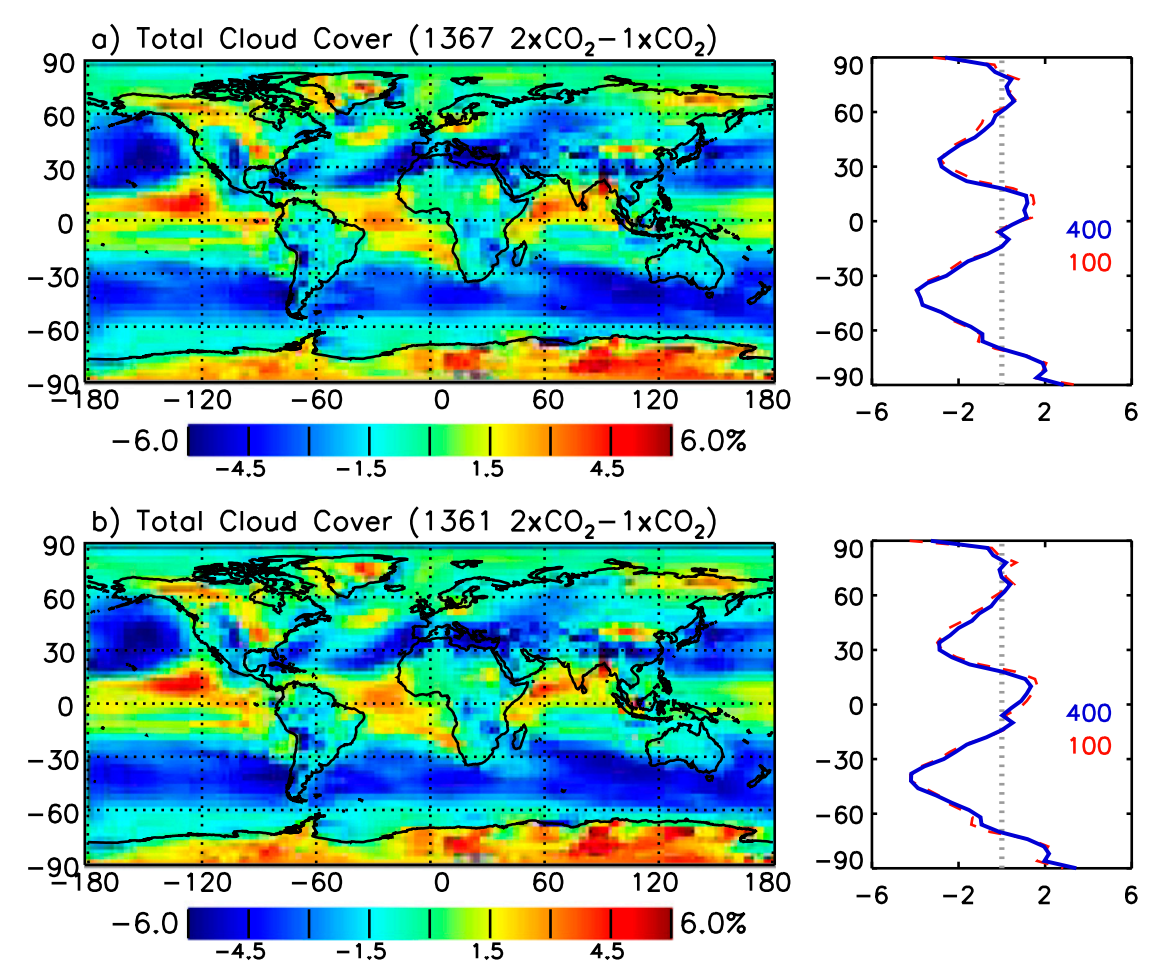

c) Difference of $2 \times \mathrm{CO}_{2}-1 \times \mathrm{CO}_{2}$ Changes
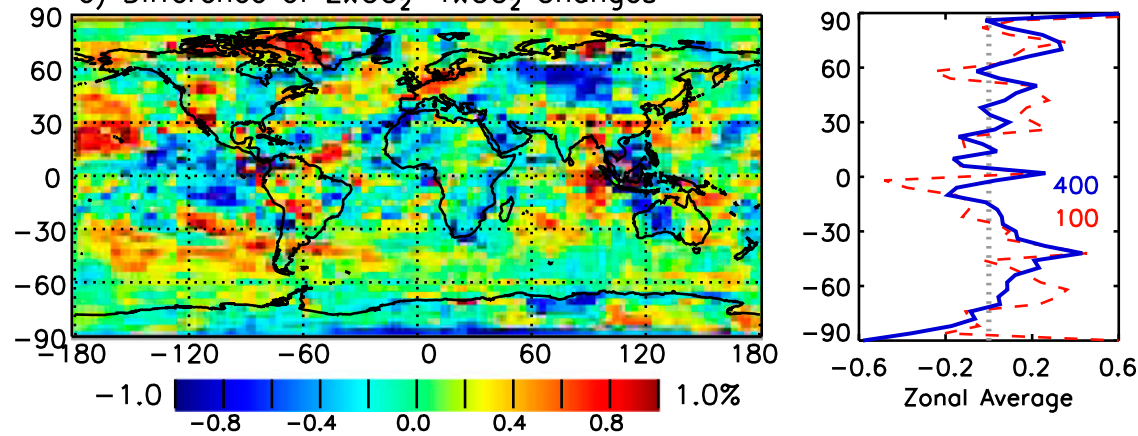

FIG. 7. Changes for years 101-500 in total cloud cover in Model 3 simulations of climate response to doubled $\mathrm{CO}_{2}$ concentrations with input solar irradiance value (a) TSI = $1367.0 \mathrm{~W} \mathrm{~m}^{-2}$, run $3-$ run 1 , and (b) TSI $=1361.3 \mathrm{~W} \mathrm{~m}^{-2}$, run $4-$ run 2. (c) The differences of the changes [(a) minus (b)]. Zonal averages are shown on the right.

(Fig. 7), surface air temperature (Fig. 8), sea level pressure (Fig. 9), precipitation (Fig. 10), and total ozone (Fig. 11), for the $2 \times \mathrm{CO}_{2}$ minus $1 \times \mathrm{CO}_{2}$ climate change simulations using the higher solar irradiance value $\left(1367.0 \mathrm{~W} \mathrm{~m}^{-2}\right)$. For comparison, the middle panels in each of the five figures show the corresponding changes using the lower solar irradiance value $\left(1361.3 \mathrm{~W} \mathrm{~m}^{-2}\right)$, and in the bottom panels are the differences between the top and middle panels, that is, (run 3 minus run 1 ) minus (run 4 minus run 2). In each case, the patterns in the top panel and the middle panel are visually quite similar so that, at least qualitatively, the Model 3 parameterized compensation for different absolute solar irradiance values successfully mitigates differences in simulated climate change.

Total cloud cover increases in some regions and decreases in others as climate changes in response to $2 \times \mathrm{CO}_{2}$, by up to $6 \%$ (Figs. $7 \mathrm{a}, \mathrm{b}$ ). The overall pattern of cloud cover response, irrespective of the solar irradiance value, is associated with increased upward motion in the tropics, owing to greater latent heat release as the climate warms in response to increasing greenhouse gas concentrations; subsidence increases in the subtropics and midlatitudes. Many anthropogenic warming experiments demonstrate this response (e.g., Solomon et al. 2007, Fig. 10.10), which is a combination of an expanded 

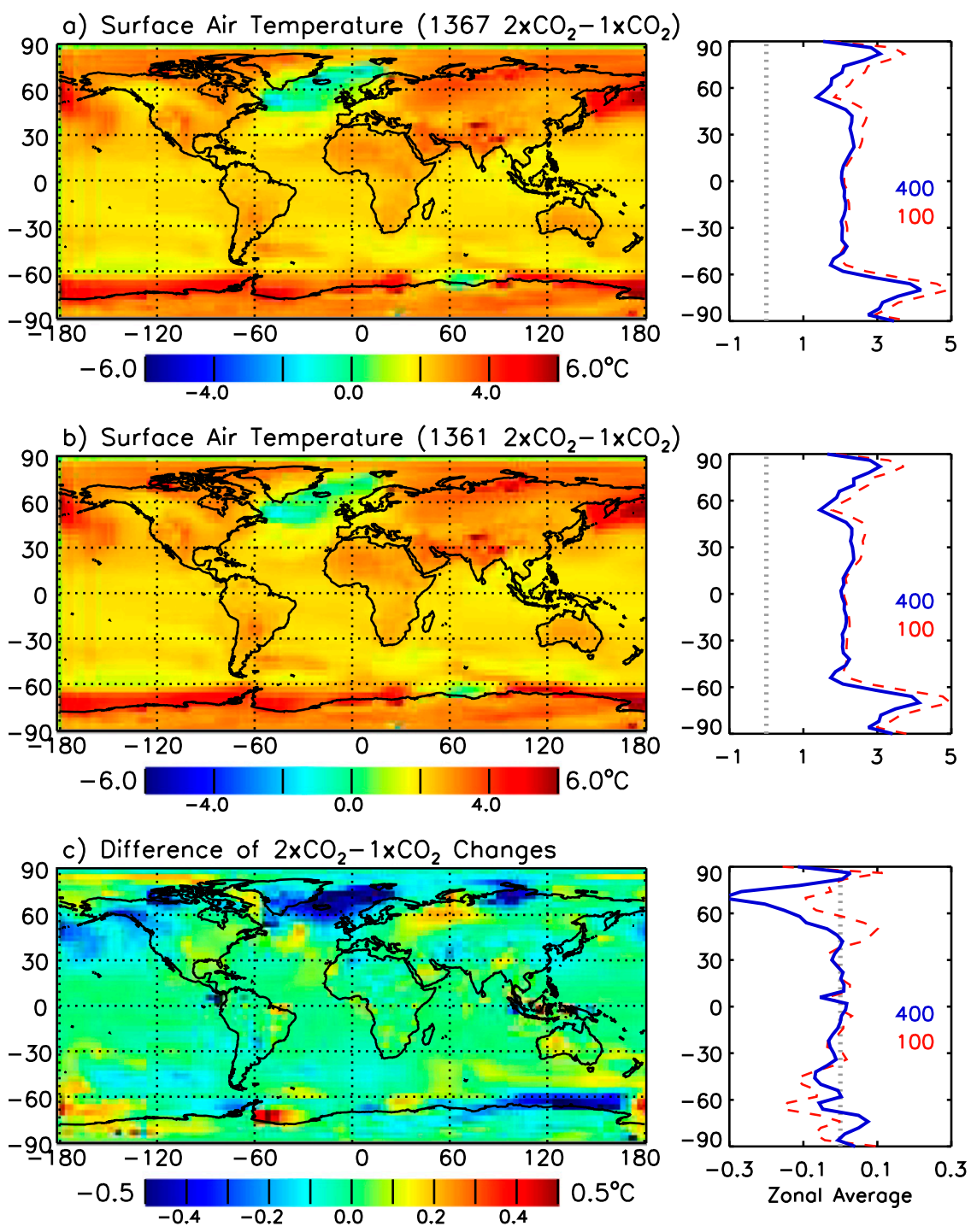

FIG. 8. As in Fig. 7, but for surface air temperature.

Hadley Cell influence and reduced extratropical storm intensity owing to reduced temperature gradients (higher latitudes warm more than lower latitudes). With a higher solar irradiance value, Model 3 underestimates the increase in cloud cover in the eastern Pacific and tropical western Pacific in the vicinity of Indonesia (Fig. 7c). While not negligible, these differences are generally less than $1 \%$ (16\% relatively). They occur in regions where cloud cover was greater in the $1 \times \mathrm{CO}_{2}$ run with the higher solar irradiance value, so the effect of reducing surface energy in the $1 \times \mathrm{CO}_{2}$ simulations seems to limit the increase in the $2 \times \mathrm{CO}_{2}$ simulations.

Corresponding changes in annual surface air temperature in response to doubled $\mathrm{CO}_{2}$ concentrations also have a characteristic pattern, independent of the absolute solar irradiance value (Figs. 8a,b), with relatively more warming at higher latitudes and over continental regions (e.g., Eurasia), aided by snow cover reduction, compared to nearby oceans. The North Atlantic warms less than surrounding regions owing to a reduction in North Atlantic Deep Water production and associated poleward ocean heat transport, again similar to many climate warming experiments (e.g., Solomon et al. 2007, Fig. 10.8). However, there is a tendency for the areas that were warmer in the respective $1 \times \mathrm{CO}_{2}$ simulations to have less warming in the climate change experiment: It was usually warmer in the $1 \times \mathrm{CO}_{2}$ run owing to the locally reduced cloud cover needed to achieve global energy balance with the higher input solar irradiance. Part of the reason for the reduced warming with climate change is that in these regions there is now less cloud cover to lose. 

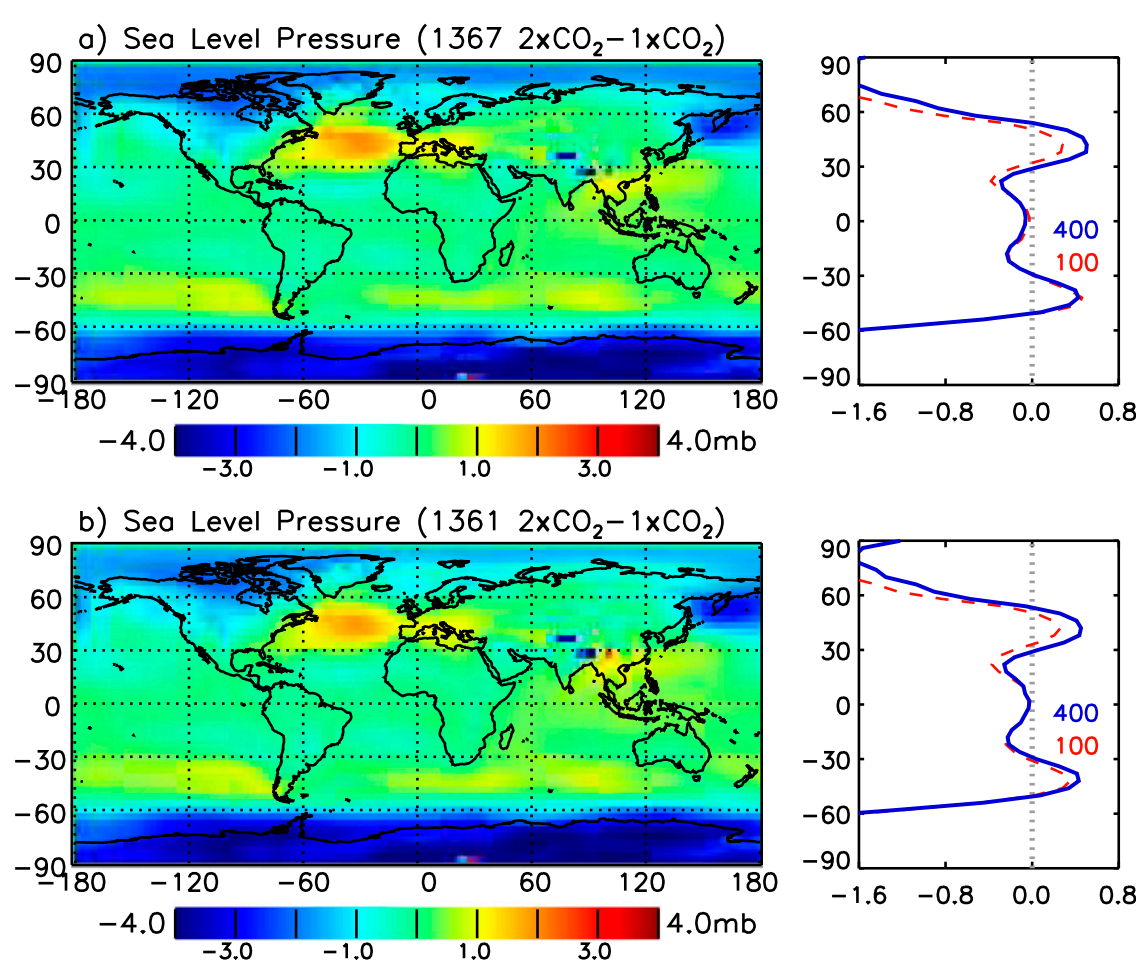

c) Difference of $2 \times \mathrm{CO}_{2}-1 \times \mathrm{CO}_{2}$ Changes
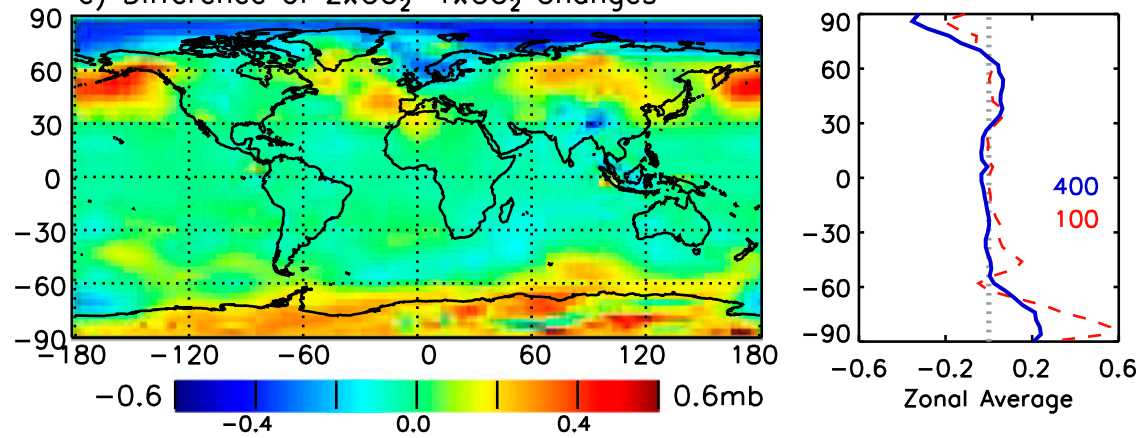

FIG. 9. As in Fig. 7, but for sea level pressure.

Sea ice changes arising from the doubled $\mathrm{CO}_{2}$ concentrations also contribute. Where there is less sea ice in the $1 \times \mathrm{CO}_{2}$ runs, less can potentially be lost, and with the larger solar irradiance value there is less sea ice. Differences in sea ice between the two climate change simulations are relatively large, on the order of tens of percent (relatively) in both hemispheres. Using the larger solar irradiance value results in an underestimate of North Atlantic warming, specifically, and, more generally, higher-latitude warming in both hemispheres.

The sea level pressure differences resulting from doubled atmospheric $\mathrm{CO}_{2}$ concentrations are shown in Figs. $9 \mathrm{a}$ and $9 \mathrm{~b}$. Both hemispheres have lower pressure at higher latitudes, irrespective of the solar irradiance value, which is an expression at the surface of more positive northern and southern annular modes. This response is also a general feature of climate warming experiments (e.g., Rind et al. 2005; Solomon et al. 2007) and is due to 1) greater warming in the tropical upper troposphere relative to extratropical latitudes, leading (from the thermal wind relationship) to 2) increased zonal west winds in the subtropics and hence 3 ) greater equatorward planetary wave refraction, and thus 4) greater poleward momentum transport (e.g., Rind et al. 2005). Although the basic pattern remains the same, the effect on sea level pressure of using a larger value of solar irradiance (Fig. 9c) is greater reduction (less reduction) in the Northern Hemisphere (Southern Hemisphere), as explained below. Unlike the situation with the two $1 \times \mathrm{CO}_{2}$ runs (Fig. 3), the advective differences due to these slightly different sea level pressure responses have only a slight influence on the resulting surface air 

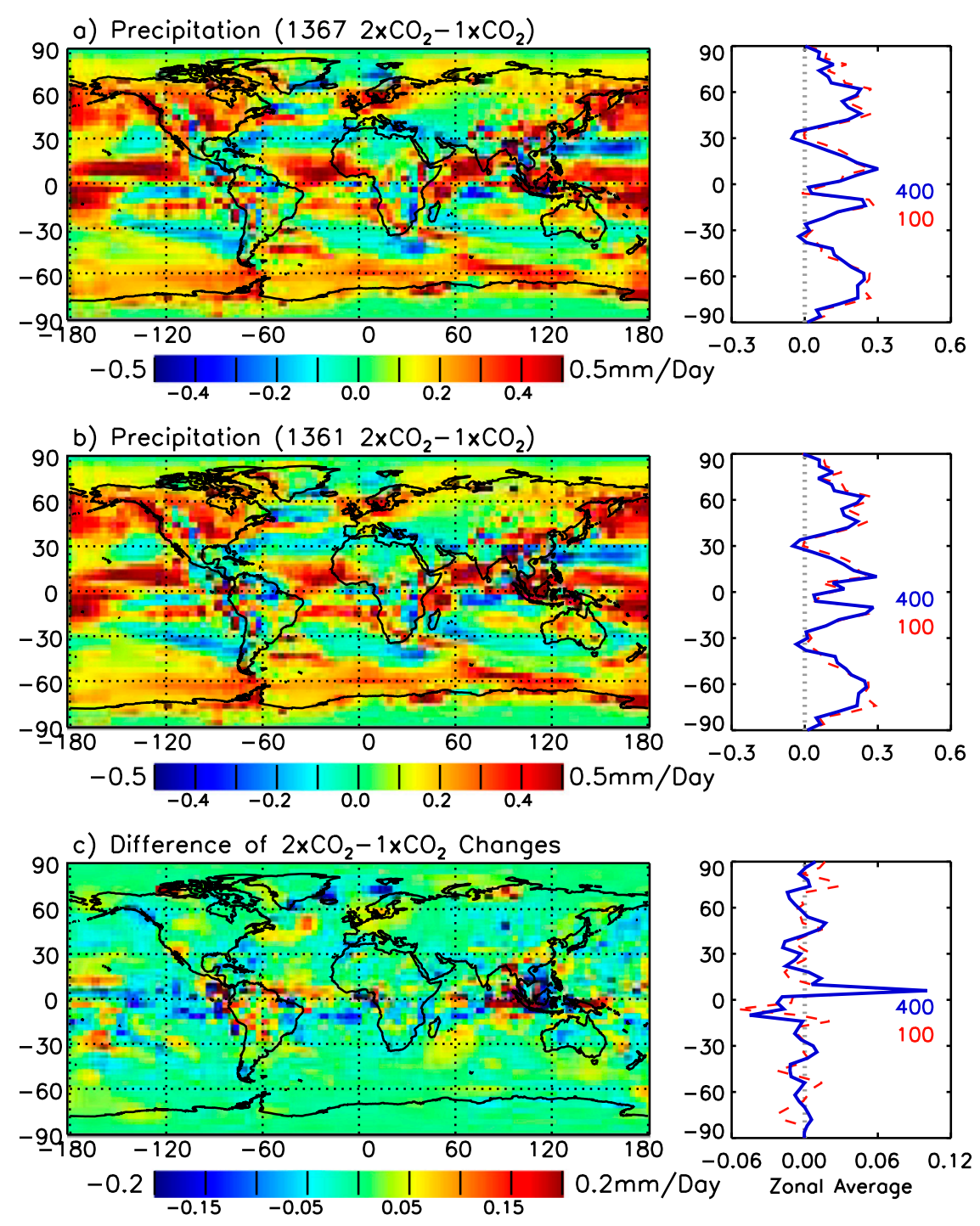

FIG. 10. As in Fig. 7, but for precipitation.

temperature differences (Fig. 8), which are dominated by the radiative responses as discussed above.

The precipitation anomalies for the double $\mathrm{CO}_{2}$ simulations, shown in Figs. 10a and 10b, although not identical on the scale of several grid boxes, are quite similar when using two different solar irradiance values; both show increased tropical upwelling and subtropical subsidence in response to warming from increased greenhouse gas concentrations (e.g., Solomon et al. 2007, Fig. 10.12). The primary differences, evident in Fig. 10c, suggest that using the higher solar irradiance value for climate change simulations may underestimate the increase in precipitation (as it did for cloud cover) in the eastern and especially western Pacific regions. Again, where cloud cover was greater in the $1 \times \mathrm{CO}_{2}$ run, and the surface energy less, the precipitation increase was limited.
Total ozone column changes associated with doubled $\mathrm{CO}_{2}$ climate change simulated using the higher and lower solar irradiance values are shown in Figs. 11a and 11b. According to Model 3, in a warmer climate total ozone increases in the extratropics and decreases slightly in the tropics. The extratropical increases are the result of accelerated ozone photochemical generation between 1 and $10 \mathrm{mb}$ associated with colder stratospheric temperatures, as in this region the increased $\mathrm{CO}_{2}$ concentrations enhance radiative cooling to space. Figure 12a illustrates the vertical profile of the zonal mean temperature change for the doubled $\mathrm{CO}_{2}$ climate, with cooling evident everywhere above about $100 \mathrm{mb}$. Figure 12c shows the corresponding vertical profile of the zonal mean change in ozone photochemistry. The increased ozone is advected poleward and downward at 

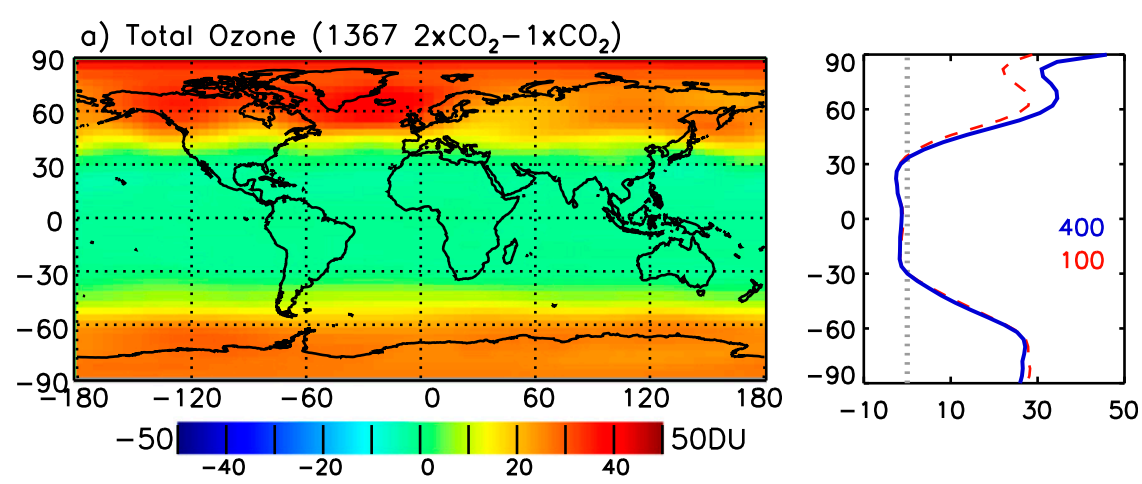

b) Total Ozone (1361 $\left.2 \times \mathrm{CO}_{2}-1 \times \mathrm{CO}_{2}\right)$
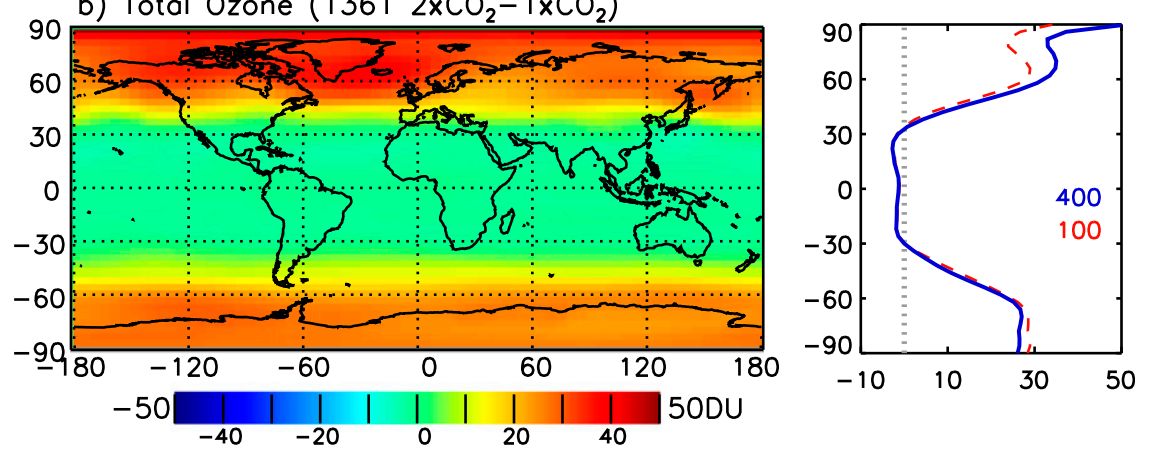

c) Difference of $2 \times \mathrm{CO}_{2}-1 \times \mathrm{CO}_{2}$ Changes
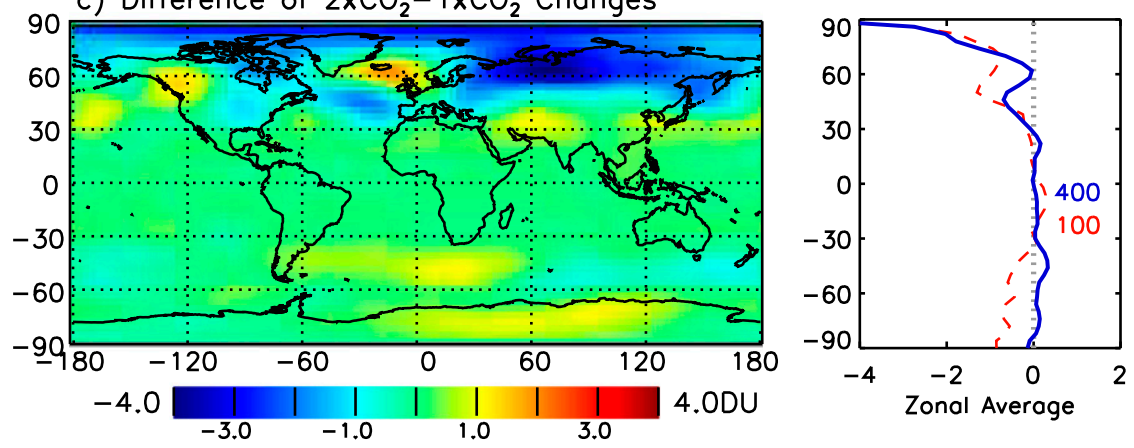

FIG. 11. As in Fig. 7, but for total ozone.

subtropical and polar latitudes as a result of the northward and vertical transport changes shown in Figs. 13a and $13 \mathrm{c}$, respectively. The increased transport is not due simply to the greater availability of ozone but also to an amplified stratospheric residual circulation in the warmer climate (e.g., Rind et al. 1990), which brings more low ozone air from the troposphere into the tropical stratosphere, explaining the tropical response.

The differences that the absolute solar irradiance value makes to simulations of total ozone in a warming climate are shown in Fig. 11c. Corresponding differences in the vertical temperature, ozone photochemistry, and transport changes are shown in Figs. 12b,d and 13b,d. While the spatial and vertical patterns of change are very similar in each of the $2 \times \mathrm{CO}_{2}$ simulations, the slightly warmer temperatures with the higher solar irradiance value $\left(0.1^{\circ}-0.2^{\circ} \mathrm{C}\right.$, Fig. $\left.6 \mathrm{a}\right)$ reduce the photochemical productivity in the upper stratosphere (by $2 \%$ overall relative to the standard run, Fig. 12d), lessening the ozone increase slightly (Table 2). This deficit is then advected to the North Pole, producing the total ozone differences evident in Fig. 11c. Note that, in Fig. 11c, total ozone over the North Atlantic is an exception to this general pattern since here the climate change experiments using higher solar irradiance produce higher total ozone. The residual circulation actually strengthens about $10 \%$ more in the $2 \times \mathrm{CO}_{2}$ simulation made with the higher solar irradiance value, as can be seen by noting that the changes in ozone vertical transport (Fig. 13d) are of roughly the same structure as the $\Delta 2 \times \mathrm{CO}_{2}$ transports [Fig. 13c, increased downward (upward) transport where there was relative downward (upward) transport in the 

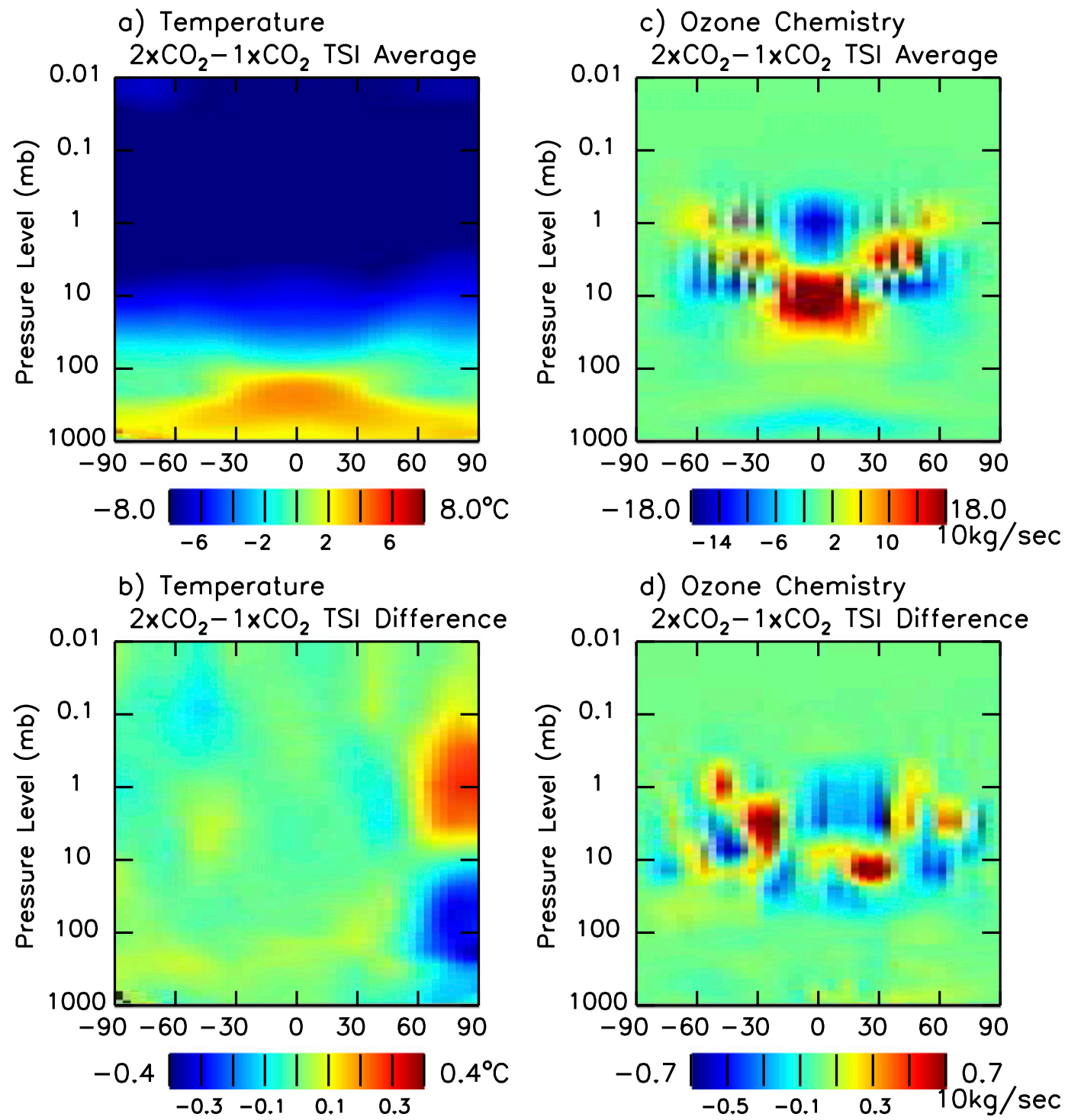

FIG. 12. Zonal average altitude profiles of the year 101-500 changes in two simulations of climate change for doubled $\mathrm{CO}_{2}$ concentrations made using two different solar irradiance values: (a) the average temperature changes and (b) the differences of the temperature changes; (c) the average changes in net photochemical production of ozone and $(\mathrm{d})$ the differences of the net photochemical production changes.

climate change run], and this occurs despite the overall reduced photochemical generation. Nevertheless, the poleward transport change in the $2 \times \mathrm{CO}_{2}$ simulation results in relatively greater ozone convergence in this region (Fig. $13 \mathrm{~b} ; \sim 66^{\circ} \mathrm{N}, 100-10 \mathrm{mb}$ ), overcoming the production deficit.

The underestimate of ozone in the Northern Hemisphere polar lower stratosphere when using the higher solar irradiance value results in relatively colder temperatures in the $2 \times \mathrm{CO}_{2}$ climate (Fig. 12b), which reduces the tropospheric stability in that region. This is then responsible for the relatively reduced sea level pressure (Fig. 9c). Note that a similar effect does not occur over the Southern Hemisphere pole-not the reduced ozone, the colder polar lower stratosphere temperatures, nor the lower sea level pressure.

How significant are differences in the doubled $\mathrm{CO}_{2}$ climate change scenarios simulated using two different absolute values of solar irradiance? To assess this, we compare the "difference of the differences" in total cloud cover, surface air temperature, sea level pressure, precipitation, and total ozone (Figs. 7c, 8c, 9c, 10c, and 11c) with the standard errors of average values of the simulations (Figs. 4 and 5b). We note that the difference 

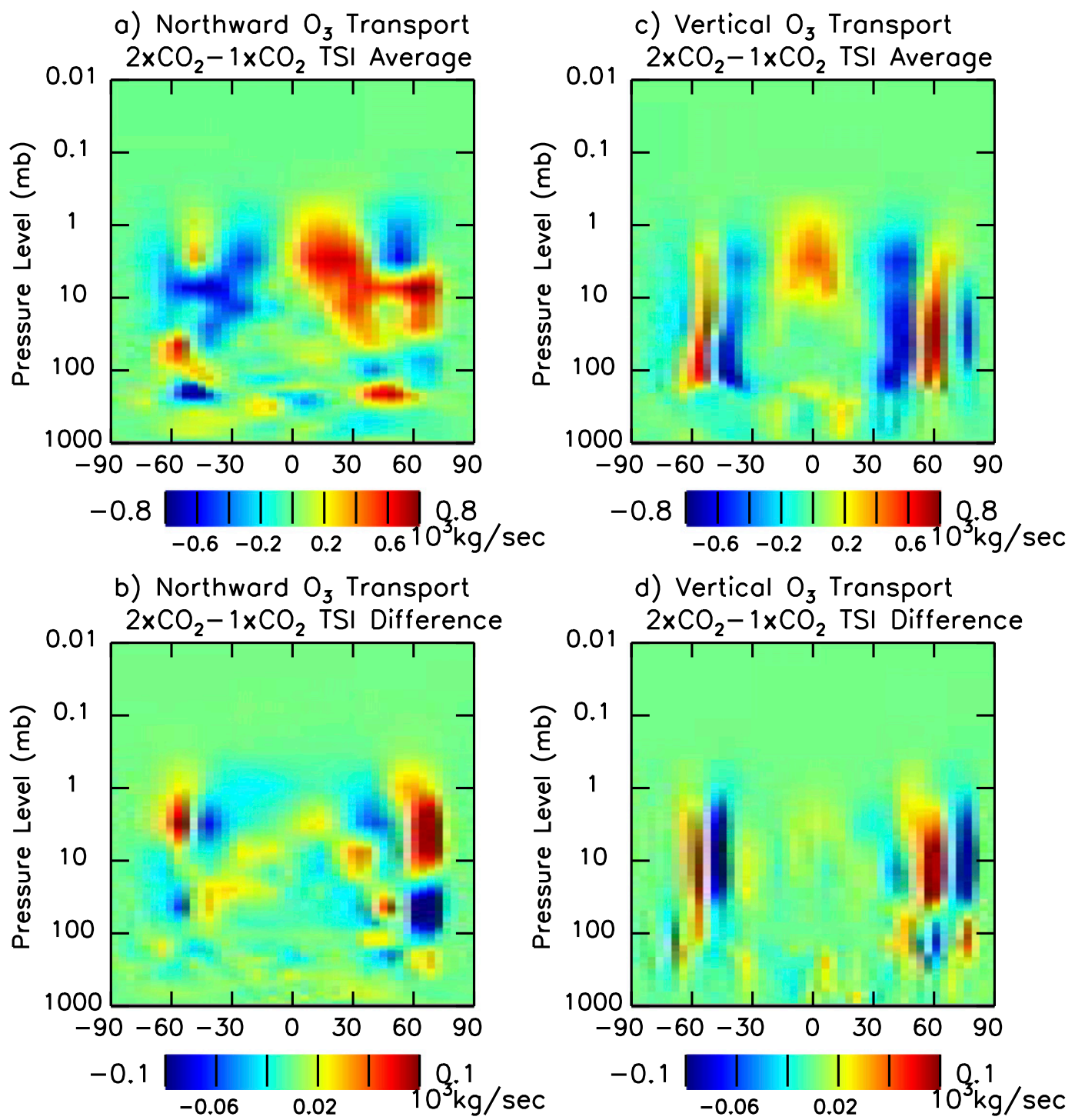

FIG. 13. As in Fig. 12, but for (a) the average changes in northward ozone transport and (b) the differences in northward ozone transport; (c) the average changes in vertical ozone transport and (d) the differences in vertical ozone transport.

of the differences deemed statistically significant are often just the more extreme aspects of a pattern of response.

A comparison of Figs. 7c and 4a indicates that, where total cloud cover changes are large, they are likely significant. So, for example, in tropical regions differences of $1 \%$ pertaining to the two different solar irradiance values (Fig. 7c) are likely significant, being a factor of 5 or so larger than the standard error in the mean total cloud cover (Fig. 4a). This can be compared with climatedriven changes of $\sim 6 \%$ (e.g., in the vicinity of Indonesia, Figs. 7a,b).

The underestimate (by more than $0.5^{\circ} \mathrm{C}$, Fig. $8 \mathrm{c}$ ) of surface air temperature changes in the North Atlantic region $\left(50^{\circ}-70^{\circ} \mathrm{N}\right)$ arising from doubled $\mathrm{CO}_{2}$ concentrations when using the higher solar irradiance value are also likely significant since the standard error in the mean surface air temperature in this region is of order $0.1^{\circ} \mathrm{C}$ (Fig. $4 \mathrm{~b}$ ). The differences of similar magnitude $\left(0.5^{\circ} \mathrm{C}\right)$ in high-latitude Southern Hemisphere climate change using the two different irradiance values are likely not as significant. Similarly the Northern Hemisphere sea level pressure differences are more significant than are the Southern Hemisphere differences (Figs. 9c and 4c).

As in the case of cloud cover, where precipitation changes are large they are likely significant (Fig. 10c compared with Fig. 4d). For example, in the tropical 
western Pacific, in the vicinity of Indonesia, the result that using higher solar irradiance likely underestimates $2 \times \mathrm{CO}_{2}$ precipitation increases by more than $50 \%$ ( $0.2 \mathrm{~mm} \mathrm{day}^{-1}$ out of the $0.5 \mathrm{~mm} \mathrm{day}^{-1}$ change) is likely significant since the standard error in the mean precipitation in this region (Fig. 4d) is less than $0.05 \mathrm{~mm}$ day $^{-1}$.

Also significant are the differences in climate-driven ozone changes for the two different values of total solar irradiance, shown in Fig. 11c, especially at high latitudes where they are a factor of 4 larger than the standard errors in the mean shown in Fig. 5b. When simulating total ozone changes for double $\mathrm{CO}_{2}$ concentrations, use of the higher solar irradiance $\left(1367.0 \mathrm{~W} \mathrm{~m}^{-2}\right)$ instead of the more accurate lower level $\left(1361.3 \mathrm{~W} \mathrm{~m}^{-2}\right)$ likely underestimates northern high-latitude total ozone changes by at least a few Dobson units.

As was done for the $1 \times \mathrm{CO}_{2}$ simulations with two different solar irradiance values, we also investigate how much of the differences between the $2 \times \mathrm{CO}_{2}$ simulations are due to the solar irradiance and cloud cover changes directly as opposed to atmosphere-ocean interactions. As noted in section 2, we use the same doubled $\mathrm{CO}_{2}$ sea surface temperatures changes in runs $3 \mathrm{~S}$ and $4 \mathrm{~S}$. The major temperature differences in Fig. 8c, over the northern North Atlantic and near eastern Antarctica, are not present when the sea ice and sea surface temperature changes are the same, nor are the patterns of precipitation change (Fig. 10c). These then depend primarily on the ocean-atmosphere interaction. The highlatitude sea level pressure and cloud cover changes, in contrast, do maintain some component of the pattern evident in Figs. 7c and 9c. The explanation for this lies in the stratospheric ozone response. Most of the features in Figs. 11c, 12, and 13 also appear without the sea surface temperature differences between the doubled $\mathrm{CO}_{2}$ simulations; hence, the influence on the high-latitude sea level pressure and cloud cover responses does as well.

\section{Discussion and conclusions}

The compensation approach that the GISS Model 3 climate model uses to adjust the energy balance for different absolute solar irradiance values essentially eliminates the impact of these differences on the model specifications of most climate parameters globally. Differences in regional climate that the model simulates using two different values of solar irradiance, 1367.0 and $1361.3 \mathrm{~W} \mathrm{~m}^{-2}$, are understandable, repeatable, small, and typically comparable to the model repeatability derived from the standard deviations of the last 400 years in 500-yr runs. In a few areas, for some variables, differences are more noticeable: for example, tropical cloud cover, high-latitude temperatures, regional precipitation, and high-latitude stratospheric ozone. Especially for regions away from the extratropical oceans, a number of these differences do not depend on the atmosphereocean interaction.

In the Model 3 simulations of climate change arising from doubled levels of atmospheric $\mathrm{CO}_{2}$ concentrations determined using two different solar irradiance values, regional differences apparent in the climate specifications are amplified by the climate change perturbation and, therefore, are of somewhat more consequence. Nevertheless, even here the general patterns of change are reproduced in both sets of simulations. Noticeable regional differences do appear in some cases for the same climate features that showed differences in the $1 \times \mathrm{CO}_{2}$ run: tropical cloud cover and precipitation, highlatitude temperature, and ozone. In the tropics where cloud cover is higher in the $1 \times \mathrm{CO}_{2}$ run, increases in precipitation and cloud cover are more muted. Over land where cloud cover is reduced in the $1 \times \mathrm{CO}_{2}$ run, cloud cover reductions and warming are lessened. Where sea ice is greater in the $1 \times \mathrm{CO}_{2}$ run, so is sea ice loss and warming. For these climate change experiments, where sea surface temperatures and sea ice are important (tropical precipitation, high-latitude temperature response), the ocean-atmosphere interaction is necessary; for the stratosphere, high-latitude stability and its effect on sea level pressure, it is not.

When using a higher value of solar irradiance, and in particular of UV irradiance, Model 3 overestimates ozone concentrations at high northern latitudes in the $1 \times \mathrm{CO}_{2}$ simulations. In the doubled $\mathrm{CO}_{2}$ simulations, this produces slightly warmer stratospheric temperatures, which reduces photochemical ozone production and (compared with a simulation with the same UV values) results in an underestimate of climate-induced total ozone increases at high northern latitudes. These results do not depend on ocean-atmosphere interactions.

Given the overall uncertainty of climate change simulations for future $\mathrm{CO}_{2}$ levels, the differences reported here do not greatly affect our overall confidence (or lack of it) in the estimated climate changes. Clearly models should use the most accurate solar irradiance value available, which is that measured by TIM on SORCE, but we expect that this will not substantially alter the predictions of climate change currently being made by present-day models. As climate models improve their cloud parameterizations and seek higher fidelity specification and forecasts of climate change on smaller regional scales, the requirement for the correct absolute value of solar irradiance will likely increase in importance. In particular, we expect that using the lower rather than higher value of solar irradiance in present-day 
coupled chemistry climate models, such as those used in the recent Scientific Assessment of Ozone Depletion (WMO 2011), will alter somewhat their projections of future ozone changes.

While other modeling groups likely use somewhat different compensation techniques to ensure net radiation balance for preindustrial simulations, it is unlikely that the compensation produced by the GISS procedure would "work," while others would not. Nevertheless, a comparison with other models would be useful, if for no other reason than to highlight differences in such "compensation" techniques and how they may propagate uncertainties in simulations of future climate.

Acknowledgments. NASA funded this work. SORCE TSI data are available online (at http://lasp.colorado.edu/ sorce/data/tsi_data.htm). Model simulations were made possible through a grant from the NASA HEC division.

\section{REFERENCES}

Beck, C., J. Grieser, and B. Rudolf, 2005: A new monthly precipitation climatology for the global land areas for the period 1951 to 2000. Climate status report 2004, German Weather Service Rep., 181-190.

Hickey, J. R., L. L. Stowe, H. Jacobowitz, P. Pellegrino, R. H. Maschhoff, F. House, and T. H. Vonder Haar, 1980: Initial solar irradiance determinations from Nimbus 7 cavity radiometer measurements. Science, 208, 281-281.

Huffman, G. J., and Coauthors, 1997: The Global Precipitation Climatology Project (GPCP) combined precipitation data sets. Bull. Amer. Meteor. Soc., 78, 5-20.

Hurrell, J. W., J. J. Hack, D. Shea, J. M. Caron, and J. Rosinski, 2008: A new sea surface temperature and sea ice boundary dataset for the Community Atmosphere Model. J. Climate, 21, 5145-5153.

Jones, P. D., D. H. Lister, T. J. Osborn, C. Harpham, M. Salmon, and C. P. Morice, 2012: Hemispheric and large-scale land surface air temperature variations: An extensive revision and an update to 2010. J. Geophys. Res., 117, D05127, doi:10.1029/ 2011JD017139.

Kalnay, and Coauthors, 1996: The NCEP/NCAR 40-Year Reanalysis Project. Bull. Amer. Meteor. Soc., 77, 437-471.

Kiehl, J. T., and K. E. Trenberth, 1997: Earth's annual global mean energy budget. Bull. Amer. Meteor. Soc., 78, 197-208.

Kopp, G., and J. L. Lean, 2011: A new low value of total solar irradiance: Evidence and climate significance. Geophys. Res. Lett., 38, L01706, doi:10.1029/2010GL045777.

Legates, D. R., and C. J. Willmott, 1990: Mean seasonal and spatial variability in global surface air temperature. Theor. Appl. Climatol., 41, 11-21.
Loeb, N. G., J. M. Lyman, G. C. Johnson, R. P. Allan, D. R. Doelling, T. Wong, B. J. Soden, and G. L. Stephens, 2012: Observed changes in top-of-the-atmosphere radiation and upper-ocean heating consistent within uncertainty. Nat. Geosci., 5, 110-113, doi:10.1038/NGEO1375.

McLinden, C. A., S. C. Olsen, B. Hannegan, O. Wild, M. J. Prather, and J. Sundet, 2000: Stratospheric ozone in 3-D models: A simple chemistry and cross-tropopause flux. J. Geophys. Res., 105 (D11), $14653-14655$.

Rind, D., R. Suozzo, N. K. Balachandran, and M. J. Prather, 1990: Climate change and the middle atmosphere. Part I: The doubled $\mathrm{CO}_{2}$ climate. J. Atmos. Sci., 47, 475-494.

- D. Shindell, J. Perlwitz, J. Lerner, P. Lonergan, J. Lean, and C. McLinden, 2004: The relative importance of solar and anthropogenic forcing of climate change between the Maunder Minimum and the present. J. Climate, 17, 906-929.

_ J. Perlwitz, and P. Lonergan, 2005: AO/NAO response to climate change: 1 . Respective influences of stratospheric and tropospheric climate changes. J. Geophys. Res., 110, D12107, doi:10.1029/2004JD005103.

— J. Lerner, J. Jonas, and C. McLinden, 2007: The effects of resolution and model physics on tracer transports in the NASA Goddard Institute for Space Studies general circulation models. J. Geophys. Res., 112, D09315, doi:10.1029/ 2006JD007476.

— J. Jean, J. Lerner, P. Lonergan, and A. Leboissitier, 2008: Exploring the stratospheric/tropospheric response to solar forcing. J. Geophys. Res., 113, D24103, doi:10.1029/ 2008JD010114.

Rottman, G. J., T. N. Woods, and V. L. George, 2005: The Solar Radiation and Climate Experiment (SORCE). Sol. Phys., 230, 360-417.

Russell, G. L., J. R. Miller, and D. Rind, 1995: A coupled atmosphere-ocean model for transient climate change studies. Atmos. Ocean, 33, 683-730.

Schmidt, G. A., and Coauthors, 2006: Present-day atmospheric simulations using GISS ModelE: Comparison to in situ, satellite, and reanalysis data. J. Climate, 19, 153-192.

Shea, D. J., 1986: Climatological Atlas: 1950-1979. NCAR Tech. Note NCAR/TN-269+STR, 35 pp. and 10 microfiche.

Solomon, S., D. Qin, M. Manning, Z. Chen, M. Marquis, K. Averyt, M. Tignor, and H. L. Miller Jr., Eds., 2007: Climate Change 2007: The Physical Science Basis. Cambridge University Press, 996 pp.

Uppala, S. M., and Coauthors, 2005: The ERA-40 Re-Analysis. Quart. J. Roy. Meteor. Soc., 131, 2961-3012, doi:10.1256/ qj.04.176.

WMO, 2011: Scientific assessment of ozone depletion: 2010. World Meteorological Organization Global Ozone Research and Monitoring Project Rep. 52, 517 pp.

Yao, M.-S., and A. Del Genio, 1999: Effects of cloud parameterization on the simulation of climate changes in the GISS GCM. J. Climate, 12, 761-779. 